\title{
DÜBLIN
}

Technological University Dublin

ARROW@TU Dublin

\section{Nanotechnology Solutions for Global Water Challenges}

\author{
Aine Whelan \\ Technological University Dublin, aine.whelan@tudublin.ie \\ Niall B. McGuinness \\ Institute of Technology, Sligo \\ Mary Garvey \\ Institute of Technology, Sligo
}

See next page for additional authors

Follow this and additional works at: https://arrow.tudublin.ie/scschcpsbk

Part of the Chemicals and Drugs Commons

\section{Recommended Citation}

Whelan, A. M et al. (2015) Nanotechnology Solutions for Global Water Challenges. Ch. 18 in Water Challenges and Solutions on a Global Scale, Loganathan et al, ACS Symposium Series, Washington DC, American Chemical Society, 2015.

This Book Chapter is brought to you for free and open access by the School of Chemical and Pharmaceutical Sciences at ARROW@TU Dublin. It has been accepted for inclusion in Books/Book chapters by an authorized administrator of ARROW@TU Dublin. For more information, please contact arrow.admin@tudublin.ie, aisling.coyne@tudublin.ie,gerard.connolly@tudublin.ie.

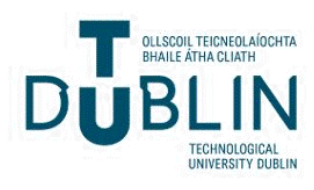




\section{Authors}

Aine Whelan, Niall B. McGuinness, Mary Garvey, Honey John, Chun Zao, Geshan Zhang, Dionysios D. Dionysiou, J. Anthony Byrne, and Suresh C. Pillai 


\title{
Chapter 18
}

\section{Nanotechnology Solutions for Global Water Challenges}

\author{
Niall B. McGuinness, ${ }^{1,2}$ Mary Garvey, ${ }^{1,2}$ Aine Whelan, ${ }^{3}$ Honey John, ${ }^{4}$ \\ Chun Zhao, ${ }^{5}$ Geshan Zhang, 6 Dionysios D. Dionysiou, ${ }^{6}$ \\ J. Anthony Byrne, ${ }^{7}$ and Suresh C. Pillai ${ }^{*}, 1,2$ \\ 1Nanotechnology Research Group, Department of Environmental Sciences, \\ Institute of Technology Sligo, Sligo, Ireland \\ ${ }^{2}$ Centre for Precision Engineering, Materials and Manufacturing Research, \\ Institute of Technology Sligo, Sligo, Ireland \\ ${ }^{3}$ School of Chemical and Pharmaceutical Sciences, \\ Dublin Institute of Technology, Kevin St., Dublin 8, Ireland \\ 4Department of Chemistry, Indian Institute of Space Science and Technology, \\ Thiruvananthapuram, Kerala- 695547, India \\ 5Key Laboratory of the Three Gorges Reservoir Region's Eco-Environment, \\ Ministry of Education, Chongqing University, \\ Chongqing 400045, People's Republic of China \\ 6Environmental Engineering and Science Program, University of Cincinnati, \\ Cincinnati, Ohio, OH 45221-0012, United States \\ ${ }^{7}$ Nanotechnology and Integrated BioEngineering Centre, \\ School of Engineering, University of Ulster, \\ Newtownabbey, Northern Ireland, BT37 0QB, United Kingdom \\ *E-mail: pillai.suresh@itsligo.ie.
}

The lack of clean and safe drinking water is responsible for more deaths than war, terrorism and weapons of mass destruction combined. This suggests contaminated water poses a significant threat to human health and welfare. In addition, standard water disinfection approaches such as sedimentation, filtration, and chemical or biological degradation are not fully capable of destroying emerging contaminants (e.g. pesticides, pharmaceutical waste products) or certain types of bacteria (e.g. Cryptosporidium parvum). Nanomaterials and nanotechnology based devices can potentially be employed to solve the challenges posed by various contaminants and 
microorganisms. Nanomaterials of different shapes, namely nanoparticles, nanotubes, nanowires and fibers have the ability to function as adsorbents and catalysts. These possess an expansive array of physicochemical characteristics deeming them highly attractive for the production of reactive media for water membrane filtration, a vital step in the production of potable water. As a result of their exceptional adsorptive capacity for water contaminants, graphene based nanomaterials have emerged as an area of significant importance in the area of membrane filtration and water treatment. In addition, Advanced Oxidation Processes (AOPs) together with or without sources of light irradiation or ultrasound, have been found to be promising alternatives for water treatment at near ambient temperature and pressure. Furthermore, the uses of visible light active titanium dioxide photocatalysts and photo-Fenton processes have shown significant potential for water purification. A wide variety of nanomaterial based sensors, for the monitoring of water quality, have also been reviewed in detail. In conclusion, the rapid and continued growth in the area of nanomaterial based devices offers significant hope for addressing future water quality challenges.

\section{Introduction}

The availability and steady supply of drinking water is more and more difficult to achieve and this is becoming increasingly challenging, particularly in the developing world. It was estimated that in 2010 there were 748 million people throughout the world without access to improved water sources for drinking and many more rely on water that is not safe to drink due to contamination with pathogenic microorganisms (1). Polluted water constitutes a major threat to human health and welfare (2). According to the World Health Organization (WHO), 2 million people die every year from diarrheal diseases, attributed to unsafe water, sanitation and hygiene. Millions of people are exposed to unsafe levels of naturally occurring arsenic and fluoride in water, which can result in cancer and skeletal damage. Indeed, a report published in the medical journal The Lancet asserted that poor water sanitation and a lack of safe drinking water results in a greater number of deaths than war, terrorism and weapons of mass destruction combined (3). Furthermore, the reuse of wastewater is becoming increasingly important due to water scarcity throughout the globe, and it is vital to ensure that water for reuse is free from pathogenic microorganisms, especially for food-crop irrigation and recharge of aquifers. Solar energy is free and ubiquitous on the Earth's surface and the exposure of contaminated water to solar irradiation can make water safer to drink through the inactivation of pathogenic microorganisms by a combination of ultraviolet (UV) photolytic mechanisms (direct and indirect) and an increase in temperature. Many countries have started working on various 
filtration systems to separate drinking water from dissolved ions, for example, sodium chloride from sea water, arsenic type carcinogenic chemical elements from ground water etc. Nanomaterial based composites are upcoming materials within the area of water filtration. For instance, the creation of nanopores in graphene and graphene oxide (GO) membranes makes them a very promising material for future water technologies, especially in the areas of desalination, water purification and arsenic removal. However, several challenges have to be met such as controlled creation of nanopores, maintaining the structural properties of nanomaterials, selective exclusion of ions from water etc. One of the major priorities of environmental monitoring today is the rapid and accurate detection of contaminants in water $(4,5)$. Therefore, it is of critical importance to develop robust, cost effective water cleaning devices and sensors that can accurately and rapidly detect and decontaminate the wide range of water contaminants, including heavy metal cations, organic pollutants and pathogenic bacteria and their toxins. In addition, the challenges posed in developing sensors include the extremely low concentrations of certain contaminants in water and the complexity of the water matrix. A number of nanotechnological solutions to address these challenges are described in the following sections.

\section{Solar Disinfection of Water}

The solar disinfection (SODIS) method is a protocol for the application of solar disinfection for drinking water (Figure 1). Clear 1-2 L polyethylene terephthalate (PET) bottles are filled with raw water and then exposed to the sun for 6-8 $\mathrm{h}$ (one day of sunshine) or two consecutive days in cloudy conditions. The SODIS water will possess a reduced load of pathogens and therefore be safer to drink. SODIS is recognized by the WHO as an appropriate Household Water Treatment intervention for the disinfection of water, particularly in regions where lack of access to safe water is an issue, including emergency situations. It is estimated that SODIS is currently being used by nearly more than 5.5 million people around the world, mainly in the developing regions of Asia, Africa and Latin America. SODIS has been compared with other household water treatment and storage methods and it was found that SODIS was slightly less cost-effective when compared to chlorination; however, the latter requires the distribution of sodium hypochlorite or chlorine tablets, whereas solar energy is widely and freely available (6).

\section{Photocatalytic Enhancement of Solar Disinfection}

Photocatalysis is the acceleration of a photoreaction by the presence of a catalyst. When a semiconductor (e.g. titanium dioxide $\left.\left(\mathrm{TiO}_{2}\right)\right)$ is irradiated with electromagnetic radiation of wavelength equal to or greater than its band gap, the absorption of photons gives rise to the formation of electron-hole pairs $\left(\mathrm{e}^{-}\right.$and $\left.\mathrm{h}^{+}\right)$ in the semiconductor. These charge carriers can recombine with the energy being 
re-emitted as light or heat, or they may migrate to the catalyst surface. If the charge carriers reach the semiconductor particle surface they may participate in redox reactions. In the presence of water and oxygen $\left(\mathrm{O}_{2}\right)$, the redox reactions at the surface of the photocatalyst will result in the production of reactive oxygen species (ROS). The ROS can not only destroy a large variety of chemical contaminants in water but also cause fatal damage to microorganisms (Figure 2).

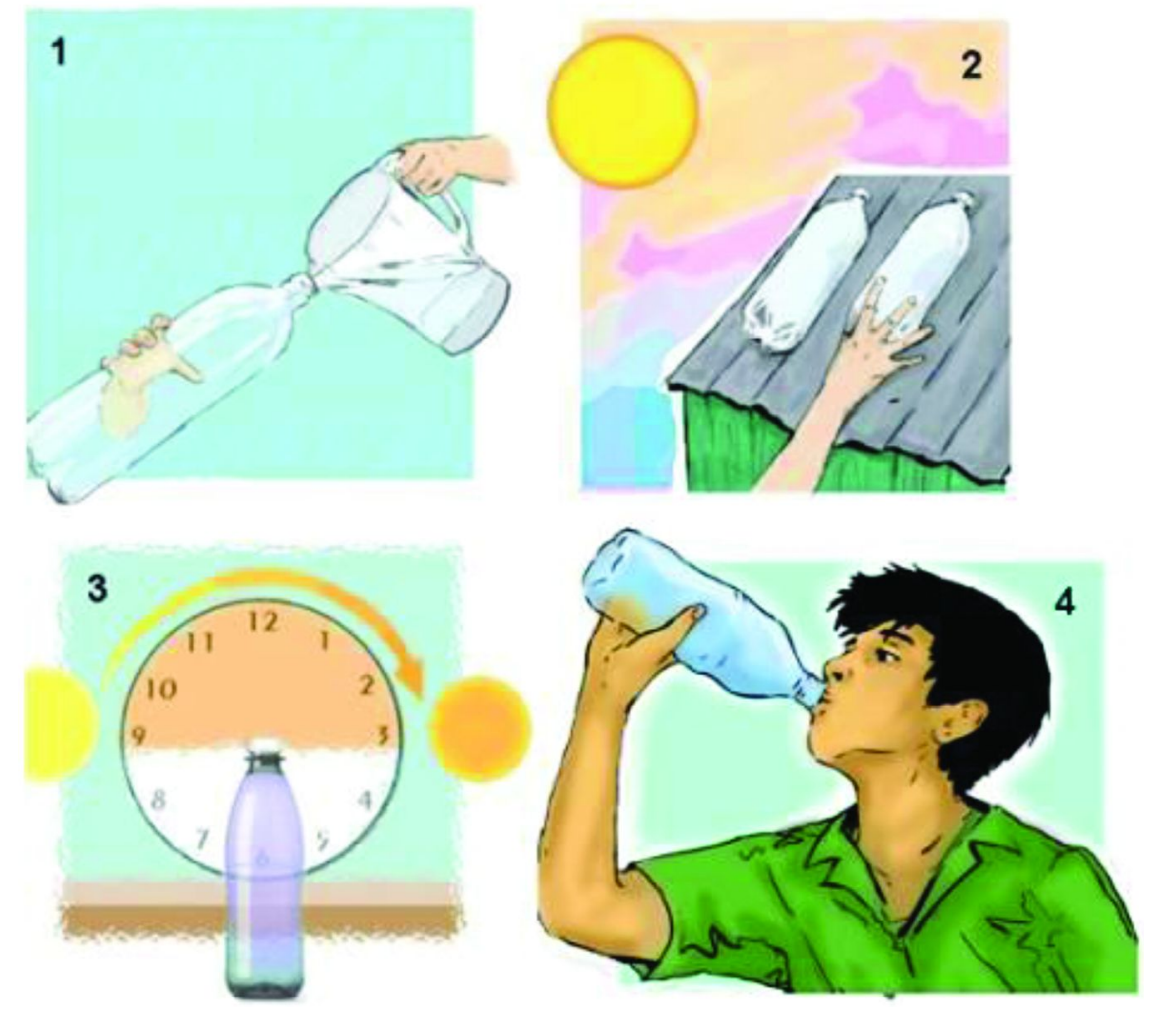

Figure 1. SODIS process. (Reproduced with permission from reference (6). Copyright 2014 Royal Society of Chemistry.)

In 1985, Matsunaga et al. first reported the inactivation of bacteria using semiconductor photocatalysis (7). Since then, there have been a large number of research studies reporting the use of photocatalysis to inactivate microorganisms including bacteria (cells $(8,9)$, spores and biofilms $(10)$, viruses $(11)$, protozoa (12), fungi (13) and algae) (14). Photocatalytic disinfection has been reviewed by several researchers including Byrne et al. (15), McCullagh et al. (16), Malato et al. (17) and Robertson et al. (18). The majority of published research papers have focused on the assessment of novel materials, new reactor systems or the effect of experimental parameters on the rate of inactivation. A number of studies have investigated the mechanism involving ROS and their interaction with the biological structures on or within the microorganisms, and the resulting 
inactivation. Dalrymple et al. conducted a review of the mechanisms involved but concluded that the exact sequence of events leading to loss of viability is not completely clear (19). The hydroxyl radical $(\cdot \mathrm{OH})$ has been suggested to be the primary radical species responsible for microorganism inactivation, however superoxide radical anion $\left(\mathrm{O}_{2}{ }^{-}\right)$, hydroperoxyl radical $\left(\mathrm{HO}_{2}{ }^{\circ}\right)$ and hydrogen peroxide $\left(\mathrm{H}_{2} \mathrm{O}_{2}\right)$ have also been shown to contribute (20). Unlike antibiotics, ROS attack is not specific to one site or an individual pathway and the development of bacterial resistance to photocatalysis is considered to be almost impossible.

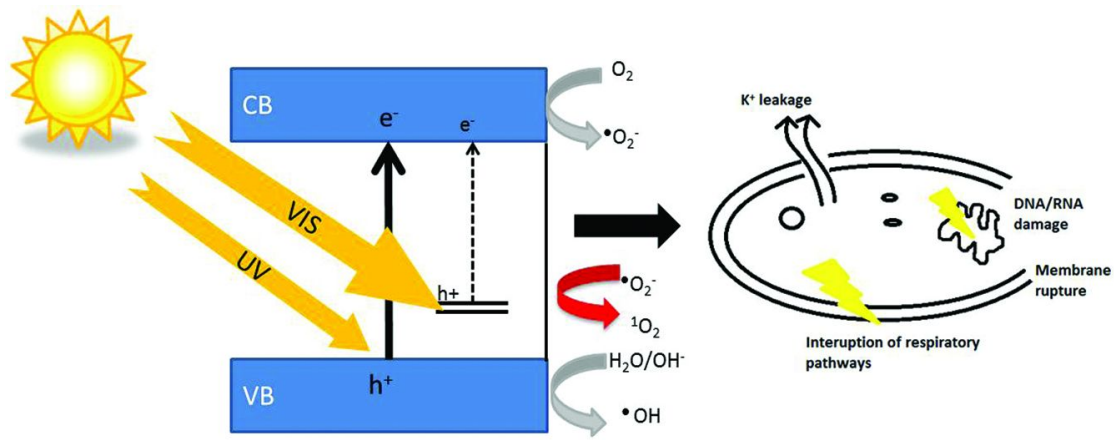

Figure 2. Schematic representation of photocatalysis mechanism on a titanium dioxide (doped and undoped). (Reproduced with permission from reference (6). Copyright 2014 Royal Society of Chemistry.)

In photocatalysis, ROS attack the microorganism from the outside initially, and then inside, destroying the sensitive metabolic processes and genetic material. The resistance of the outer layers of the organism to ROS attack determines the ability of the organism to resist. The thick protein, carbohydrate and lipid structures surrounding protozoa and bacterial spores yield greater resistance to ROS attack, when compared to viruses, fungi and bacteria, with resistance to photocatalytic inactivation observed in that order respectively (18). Given the complexity in the structure of microorganisms it is clear why the complete mechanism of photocatalytic inactivation is still not fully understood. The accepted sequence of events, taking place during photocatalytic inactivation of microorganisms, is that prolonged ROS attack results in damage of the cell wall, followed by compromise of the cytoplasmic membrane and direct attack of intracellular components.

\section{Nanocatalyst for Heterogeneous Advanced Oxidation Processes in Water Decontamination}

In recent decades, AOPs, which use oxidants (ozone $\left(\mathrm{O}_{3}\right), \mathrm{O}_{2}$, and $/$ or $\mathrm{H}_{2} \mathrm{O}_{2}$ ) and/or catalysts (transition metals, iron, and semiconductor) together with or without sources of light irradiation or ultrasound, have been found to be promising alternatives for environmental remediation, especially for water treatment at near ambient temperature and pressure (21-24). Typical AOPs include $\mathrm{H}_{2} \mathrm{O}_{2} / \mathrm{UV}$, 
$\mathrm{TiO}_{2} / \mathrm{UV}$, ozone based processes $\left(\mathrm{O}_{3} / \mathrm{UV}, \mathrm{O}_{3} / \mathrm{H}_{2} \mathrm{O}_{2}\right.$, and catalytic ozonation), and those based on the Fenton or Fenton-like reactions. These technologies can produce highly reactive free radicals, such as the hydroxyl radical $(\cdot \mathrm{OH})(25)$. The hydroxyl radical is the second strongest oxidant with an oxidation potential at $2.80 \mathrm{~V}$. It is effective at destroying organic pollutants rapidly with second-order rate constants, usually in the range of $10^{9}-10^{10} \mathrm{M}^{-1} \mathrm{~s}^{-1}$, and non-selectively with nearly all electron-rich organic compounds $(26)$, such as hydrocarbons $(23,27)$, organic dyes $(28,29)$, antibiotics $(30,31)$, pesticides $(32,33)$, landfill leachates $(34,35)$, explosives $(36-38)$, phenols $(39,40)$, and microbial contaminants $(17,41)$. Meanwhile, nanocatalysis is one of many practical applications of nanotechnology. Nanocatalysis involves the synthesis and function of catalytic materials at the nanoscale range $(<100 \mathrm{~nm})$ in the form of nanoparticles (NPs) or nanosize porous supports with controlled shapes and sizes (42). The introduction of nanocatalysts in heterogeneous AOPs has led to appreciable improvements in decontamination efficiency for water treatment due to their large specific surface area, where catalytic active sites are exposed (43). In this section, we discuss some important research studies and the application of nanocatalysts in heterogeneous AOPs for water decontamination in recent years.

\section{Advances in Ozonation Applications while Employing Nanomaterials}

Ozonation has been widely applied in water treatment throughout the world, especially for the treatment of various organic compounds (44-46). Through direct oxidation, ozone can react with organic pollutants, although it is relatively slow and selective; through indirect reaction, reactive radicals (mainly ${ }^{\circ} \mathrm{OH}$ ) can be generated via ozone decomposition in the presence of nanomaterials as catalysts for the degradation of different organics contaminants. However, the generation of $\cdot \mathrm{OH}$ is $\mathrm{pH}$ dependent, which largely limits its application (47).

Catalytic ozonation, which includes homogeneous and heterogeneous catalytic ozonation, has been widely investigated in order to improve the treatment efficiency of organic pollutants. Currently, more efforts have been focused on heterogeneous catalytic ozonation. During heterogeneous catalytic ozonation, ozone can be activated using transition metal oxide catalysts to enhance the production of hydroxyl radicals. Moreover, nanomaterial based catalysts have shown a distinctive and significant potential for the enhancement of reaction kinetics and many nanomaterials have been investigated, including metal oxides, metals or metal oxides on supports $(48,49)$.

Catalytic ozonation with $\mathrm{TiO}_{2}$ NPs was proven to provide significant improvement for nitrobenzene removal when compared with ozone alone which follows a hydroxyl radical based mechanism (50). ZnO NPs catalyzed ozonation was investigated by Tabatabaei et al. for the degradation of 4-nitrochlorobenzene (51). They found that a $\mathrm{pH}$ of 3 was the optimum $\mathrm{pH}$ for greatest removal efficiency. The effect of $\mathrm{ZnO}$ catalyst particle size on ozonation was examined in another study for the degradation of 2,4,6-trichlorophenol. This showed that the degradation efficiency follows the 
order of nanometer $>$ submicrometer $>$ micrometer $(52) . \quad \mathrm{Co}_{3} \mathrm{O}_{4}$ NPs were also employed for catalytic ozonation during phenol degradation which showed higher catalyst activity in contrast to bulk $\mathrm{Co}_{3} \mathrm{O}_{4}$ material (53). Besides, the same study found that the reaction performed at $298 \mathrm{~K}$ was faster than that at $283 \mathrm{~K}$ or $313 \mathrm{~K}$. Magnetic $\mathrm{NiFe}_{2} \mathrm{O}_{4} \mathrm{NPs}$ synthesized by Zhao et al. was also employed for catalyzing ozonation during phenol degradation which can be recovered via calcination and ozonation (54). Another study investigated the role of magnetic spinel ferrites $\left(\mathrm{MnFe}_{2} \mathrm{O}_{4}\right.$ and $\left.\mathrm{NiFe}_{2} \mathrm{O}_{4}\right)$ in catalytic ozonation during phenacetin removal, which demonstrated the magnetic properties and excellent catalytic activity of the new catalyst (55). Activated carbon coated with $\mathrm{Fe}_{3} \mathrm{O}_{4} \mathrm{NPs}$ was also used as an ozonation catalyst for the degradation of phenol and was demonstrated to promote removal efficiency. The removal efficiency was highest at neutral $\mathrm{pH}$ (56). Moreover, nano- $\mathrm{Fe}_{3} \mathrm{O}_{4}$-impregnated alumina particles was demonstrated to be effective and stable for catalyzing the ozonation of para-chlorobenzoic acid (57).

When using catalytic ozonation for the degradation of different organic compounds, catalysts would accelerate the generation of reactive radical species (e.g. $\left.{ }^{\circ} \mathrm{OH}\right)$ in the system which can eventually lower the selectivity of ozonation and improve the reaction efficiency for pollutant removal. Currently, the degradation efficiency and effectiveness of catalytic ozonation against some emerging contaminants, such as cyanotoxins, still requires further research.

\section{Advances in Heterogeneous Fenton Processes Applied in Conjunction with Nanomaterials}

The Fenton reaction, which was initially discovered by Fenton (1894) when using peroxides with iron ions for the oxidation of tartaric acid, has been developed into a variety of processes, including homogeneous Fenton process, heterogeneous catalysis, photo-Fenton process, electro-oxidation, photo-electro-oxidation process, sono-Fenton, sono-photo-Fenton, and sono-electro-Fenton (21-23). The principal Fenton reaction is shown in Eq. (1). At first, a mixture of ferrous iron and hydrogen peroxide in acidic solution produces the ${ }^{\circ} \mathrm{OH}$ (Eq. (1)). The generated ferric ions can be reduced by excess hydrogen peroxide to produce ferrous ion again and more radicals (Eq. (2)).

$$
\begin{aligned}
& \mathrm{Fe}^{2+}+\mathrm{H}_{2} \mathrm{O}_{2} \rightarrow \mathrm{Fe}^{3+}+{ }^{\circ} \mathrm{OH}+\mathrm{OH}^{-} \\
& \mathrm{Fe}^{3+}+\mathrm{H}_{2} \mathrm{O}_{2} \rightarrow \mathrm{Fe}^{2+}+{ }^{\circ} \mathrm{O}_{2} \mathrm{H}+\mathrm{H}^{+}
\end{aligned}
$$

However, the homogeneous Fenton process is impractical to apply to in situ environmental remediation. In order to maintain a $\mathrm{pH}$ of approx. 2.8, a large amount of acid must be added to the reaction solution to avoid iron precipitation and production of a large amount of ferric hydroxide sludge. On the other hand, heterogeneous Fenton processes can mediate over a wide range of $\mathrm{pH}$ values in the presence of catalyst to prevent iron hydroxide precipitation (21). A wide range of solid catalysts have been investigated using the heterogeneous Fenton processes, 
such as nano-zero valent iron (58), iron-containing zeolite (59), resin-supported $\mathrm{Fe}(\mathrm{II})$ or $\mathrm{Fe}(\mathrm{III})(60,61)$, activated carbon loaded iron (62) or copper oxide metals (63), and iron-coated pumice particles (64). Among these catalysts, nanocatalysts have certain advantages since they have high specific surface area and therefor a greater number of active sites per unit mass accompanied by a low diffusional resistance, and also are easily accessible to target molecules (23). In the next two sub-sections, we summarize recent advances in the development of nanocatalysts in heterogeneous photo-Fenton and Fenton-like processes for water treatment.

\section{Photo-Fenton Processes}

A combination of ferrous or ferric iron with hydrogen peroxide under light irradiation can produce more $\cdot \mathrm{OH}$ and increases the rate of decontamination in water treatment due to the photochemical regeneration of ferrous ions by photoreduction (Eq. (3)) (65). However, the operating cost of photo-Fenton process is much higher in terms of energy and UV-lamp consumption. Besides, the photoFenton process requires all of the catalyst be accessible to light irradiation. Thus, several strategies have been investigated to minimize cost and improve efficiency by the application of nanocatalysts or solar energy.

$$
\mathrm{Fe}(\mathrm{OH})^{2+}+\mathrm{hv} \rightarrow \mathrm{Fe}^{2+}+{ }^{\circ} \mathrm{OH}
$$

The photo-Fenton reaction, employing zero valent iron NPs as a source of iron, demonstrated an improvement for 2-chlorophenol removal compared with goethite (66). Nanoscale iron(III) catalyst, bound onto the surface of carbon binder, was investigated by Vinita et al. for the degradation of 2,4,6-trichlorophenol under solar radiation (67). They found that a $\mathrm{pH}$ of 3 and a concentration of $\mathrm{H}_{2} \mathrm{O}_{2}$ at $800 \mathrm{mg} \mathrm{L}^{-1}$ was the optimum conditions for degradation efficiency. Nanosized $\mathrm{Fe}_{3} \mathrm{O}_{4}$ particles were also applied to UV-Fenton oxidation during catechol degradation using a wide initial $\mathrm{pH}$ range (2.0-8.0), which followed a mechanism based on the generation of $\mathrm{OH}(68)$. Moreover, a pillared laponite clay-based Fe particle nanocomposite was proven to be effective and stable for the photo-Fenton mineralization of azo-dye with negligible Fe leaching (69). GO-amorphous $\mathrm{FePO}_{4}$ was also applied during the photo-Fenton degradation of Rhodamine $\mathrm{B}$ as an effective and stable heterogeneous catalyst (70). The results showed that the introduction of GO could promote the reaction by offering more active sites, increasing adsorption capacity and accelerating the $\mathrm{Fe}^{3+} / \mathrm{Fe}^{2+}$ cycle by enhancing the utilization of solar light and its electron transfer capabilities.

\section{Fenton-like Processes}

The ideal Fenton-like process will only consume $\mathrm{H}_{2} \mathrm{O}_{2}$ to generate $\cdot \mathrm{OH}$ with a recyclable catalyst at neutral $\mathrm{pH}$, without the drawbacks of Fenton reaction such as iron waste and acid $\mathrm{pH}$ values. During the Fenton-like processes, important parameters are the catalytic activity and stability of the material. The application of NPs as catalysts of Fenton-like reactions has been described by many investigators. 
Zhao et al. fabricated a perovskite-based composite $\mathrm{BiFeO}_{3} /$ carbon aerogel (BFO/CA) as a heterogeneous Fenton-like catalyst, with three-dimensional (3D) structure, nano-scaled size and high surface area, for the oxidation of ketoprofen as the target pollutant. The results showed that nano-BFO/CA retained almost all of its high catalytic activity in the $\mathrm{pH}$ range of 3-7, and exhibited very low iron leaching, even in acidic condition (71). Zeng et al. also used nano-magnetite $\left(\mathrm{Fe}_{3} \mathrm{O}_{4}\right)$ as the iron source and cathodic Fenton generation of $\mathrm{H}_{2} \mathrm{O}_{2}$ for the degradation of 4,6-dinitro-o-cresol. The magnetite was proven to be more stable, reusable and easy to separate compared to ferrous salt (72). Moreover, the presence of nitrilotriacetic acid (NTA), a biodegradable agent, was demonstrated to accelerate the degradation of carbamazepine by eighty times when using the nano- $\mathrm{Fe}_{3} \mathrm{O}_{4} / \mathrm{H}_{2} \mathrm{O}_{2}$ system over a range of $\mathrm{pH}(5.0-9.0)$ (73). The nano nickel-zinc ferrite catalyst was also applied to the Wet Peroxide Oxidation process during the degradation of 4-chlorophenol under neutral condition, exhibiting the excellent stability of the catalyst with little iron leaching after five consecutive cycles (74).

\section{Novel Photocatalytic Materials for Visible Light Activity}

Most research investigating photocatalytic disinfection is carried out using $\mathrm{TiO}_{2}$, a wide band gap semiconductor $\left(E_{\mathrm{bg}}=3.2 \mathrm{eV}\right.$ for anatase) requiring UV excitation. Only approx. $4 \%$ of the solar spectrum is in the UV domain. For solar applications, visible light active materials are desirable (Figure 3) to increase the number of photons which can be utilized.

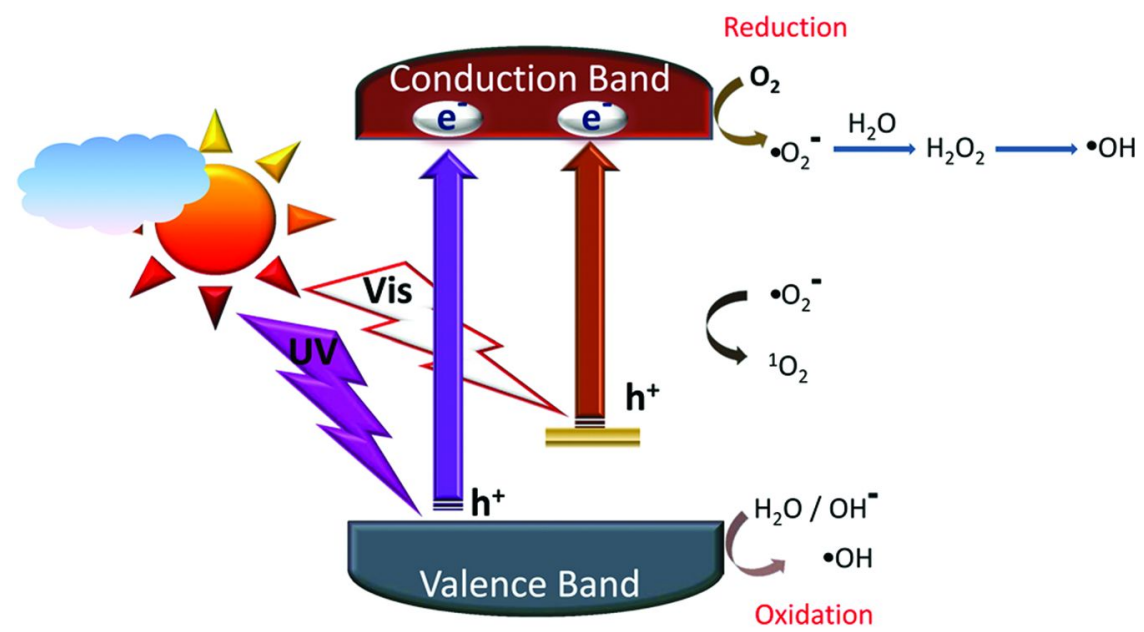

Figure 3. Visible light activation enabled by narrowing the band-gap. (Reproduced with permission from reference (75). Copyright 2014 American Chemical Society.) 
While more photons can be utilized, narrower band gap materials have a smaller voltage window to drive the redox reactions at the interface (75). The number of publications concerning the photocatalytic disinfection of water using novel visible light active materials is increasing and there are several good reviews concerning visible light active photocatalytic materials $(8,15,75)$.

Matsunaga et al. provided one of the earliest accounts of doping $\mathrm{TiO}_{2}$ for the photocatalytic inactivation of microorganisms (we use the term doped loosely to include surface loading) (7). Pt loaded $\mathrm{TiO}_{2}$ powders were demonstrated to inactivate Lactobacillus acidophilus, Saccharomyces cerevisiae and Escherichia coli within 2 hours (7). The doping of $\mathrm{ZnO}$ nanostructures has been reported to enhance the inactivation of microorganisms, either by providing a red shift in the band gap or by the dopant acting as a co-catalyst. A number of dopants including $\mathrm{Pd}$ (76), $\mathrm{Ce}$ (77), $\mathrm{Cu}$ (78), and $\mathrm{Ag}$ (79) have been reported to enhance the inactivation of microorganisms. Karunakaran et al. investigated the use of $\mathrm{ZnO}$ and $\mathrm{Ag}$ doped $\mathrm{ZnO}$ materials for the inactivation of $E$. coli. The materials were synthesized by three methods, i.e. sol-gel (79), combustion (80) and microwave synthesis $(81)$, out of which sol-gel synthesized materials have demonstrated the highest photocatalytic disinfection efficiency. Metal ion dopants are the most studied for visible light activity, although there is some disagreement over reported improvements in efficiency (82). $\mathrm{TiO}_{2}$ doped with a variety of elements have been investigated for photocatalytic disinfection. Vohra et al. have explored $\mathrm{Ag}^{+}$ doped $\mathrm{TiO}_{2} \mathrm{P} 25$ for the disinfection of indoor air. Bacillus cereus, Staphylococcus aureus, E. coli, Aspergillus niger, and MS2 bacteriophage have been successfully inactivated (83). Ag- $\mathrm{TiO}_{2}$ has also been effective for the disinfection of water (84). $\mathrm{Cu}$ and $\mathrm{S}$ doped $\mathrm{TiO}_{2}$ NPs have been effectively utilized for the inactivation of E. coli and Micrococcus lylae, respectively $(85,86)$. Nonmetal doping of $\mathrm{TiO}_{2}$ and $\mathrm{ZnO}$ with $\mathrm{C}, \mathrm{N}, \mathrm{S}, \mathrm{B}$, and halogens has been reviewed by Rehman et al. (87) and by Im et al. (88) Co-doped materials are often reported to be more effective than the single dopant materials. For example, Li et al. compared $\mathrm{N}$ and $\mathrm{C}, \mathrm{N}$ co-doping for their inactivation rate of E. coli $(89)$. Other photocatalysts, such as $\mathrm{WO}_{3}(90)$, have been doped to improve visible light activity, and present a further approach to developing new materials for disinfection (91). Rengifo-Herrera and Pulgarin reported on the photocatalytic activity of N,S co-doped and N-doped commercial anatase (Tayca TKP 102) $\mathrm{TiO}_{2}$ powders towards phenol oxidation and $E$. coli inactivation. The doped materials did not present any enhancement as compared to undoped $\mathrm{TiO}_{2}$ (Evonik Aeroxide P25) under simulated solar irradiation. They concluded that, while the $\mathrm{N}$ or $\mathrm{N}, \mathrm{S}$ co-doped $\mathrm{TiO}_{2}$ are colored materials, the localized states responsible for the visible light absorption do not play an important role in the photocatalytic activity (92).

Metal carbide, nitride and sulfide materials generally have narrower band gaps than oxide materials but they tend to undergo photoanodic corrosion in aqueous media. Some nonmetal oxide materials have been reported for the inactivation of microorganisms e.g. $\mathrm{ZnIn}_{2} \mathrm{~S}_{4}$ was reported to show visible light photocatalytic activity for the inactivation of $E$. coli (under electrochemical bias) (93). Binary metal oxides $e . g$. bismuth vanadate photocatalysts have also been reported for their disinfection properties $(94,95)$, with further enhancements in rates of disinfection reported with Ag loading as a co-catalyst (96). Titanium oxynitrides (TiON) and 
niobium oxynitrides have been reported to show activity for the disinfection of water with $\mathrm{PdO} \mathrm{NP}$ modified TiON nanofibers reported for $E$. coli inactivation under visible light (97). Also, perovskite materials such as $\mathrm{K}_{4} \mathrm{Nb}_{6} \mathrm{O}_{17}$ and $\mathrm{Ag} / \mathrm{Cu}$ modified $\mathrm{K}_{4} \mathrm{Nb}_{6} \mathrm{O}_{17}$ have been investigated for the photocatalytic inactivation of E. coli under visible light irradiation $(98,99)$.

\section{Graphene, Carbon Nanotubes, and their Composites Used in Water Technologies}

Graphene is the thinnest and strongest material known, having many fascinating properties such as a large surface to volume ratio, extraordinary high electron mobility, electrical and thermal conductivity, very high stiffness, high hydrophobicity etc. It is an array of single layer carbon atoms which are arranged in hexagonal rings $(100,101)$. Among all the properties of graphene, the hydrophobic nature of graphene can be utilized in water treatment. As we know, a hydrophobic material will naturally repel water. But when nanopores are generated on the graphene sheet, it allows water permeation. Recently, many research groups are studying the filtration capabilities of graphene sheets possessing nanopores and it is reported that graphene can remove ions like calcium, sodium and magnesium. In March 2012, Lockheed Martin Corp. patented graphene filters operating through size exclusion principle in which nanopores of graphene permit the passage of water molecules but prevent the flow of calcium $(9.9 \mathrm{~nm})$, magnesium $(8.2 \mathrm{~nm})$ and sodium $(9.7 \mathrm{~nm})(102)$. Before this work, in October 2010, researchers from Australia and Shanghai developed a new technique called capacitive deionization (CDI) which uses graphene-like nanoflakes as electrodes to purify water. In 2012, scientists from Massachusetts Institute of Technology (MIT) simulated the filtration of salts from salt water using nanoporous graphene. They have claimed that the filtration rate through this membrane is 2-3 orders higher in magnitude than current commercial desalination technologies.

Fernandez-Ibanez et al. evaluated $\mathrm{TiO}_{2}$-reduced graphene oxide (RGO) composites for the disinfection of water contaminated with $E$. coli cells and Fusarium solani spores, under natural sunlight (Figure 4) (103). Rapid water disinfection was observed with both $E$. coli and $F$ solani. An enhanced rate in the $E$. coli inactivation efficiency was observed when the $\mathrm{TiO}_{2}-\mathrm{RGO}$ composite was compared to $\mathrm{TiO}_{2}$ (Evonik Aeroxide P25). The disinfection efficiency was also evaluated using filtered sunlight, where the major part of the solar UVA was cut-off $(\lambda>380 \mathrm{~nm})$ using a Plexiglass screen. In this case, a much greater time was required for the inactivation of $E$. coli using $\mathrm{TiO}_{2} \mathrm{P} 25$, but the same inactivation rate was observed for $\mathrm{TiO}_{2}-\mathrm{RGO}$. This indicated that visible light activity could be attributed to singlet oxygen production by the $\mathrm{TiO}_{2}-\mathrm{RGO}$ composites which would lead to $E$. coli inactivation. 

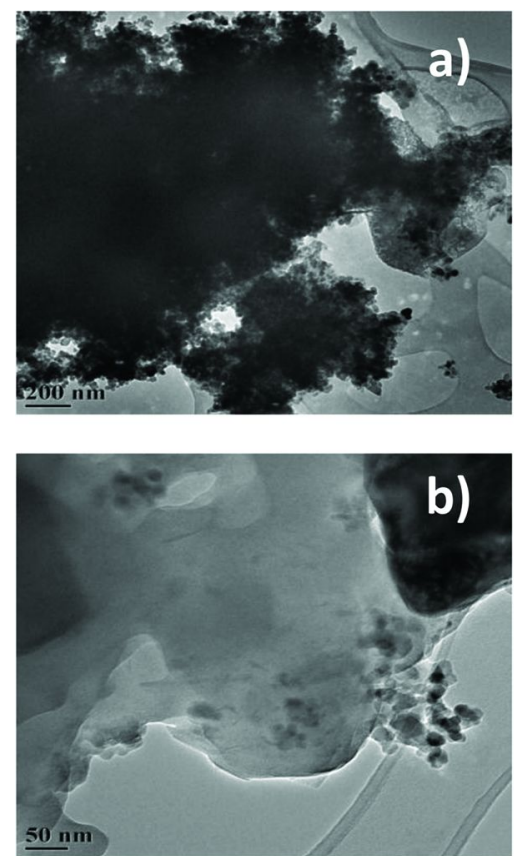

c)

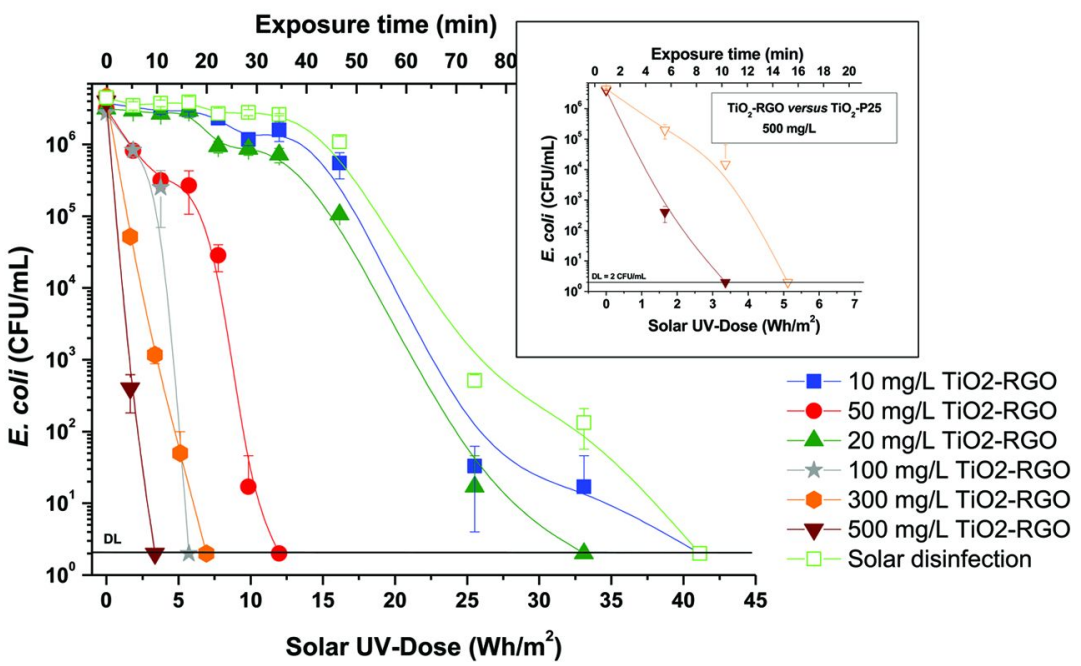

Figure 4. a) $\mathrm{TiO}_{2}-\mathrm{GO}$ aggregate before photo-reduction, b) $\mathrm{TiO}_{2}-\mathrm{RGO}$ after $U V$ assisted photo-reduction and c) E. coli inactivation at several $\mathrm{TiO}_{2}-\mathrm{RGO}$ concentrations. Figure inserts shows the efficiency of $\mathrm{TiO}_{2}-\mathrm{RGO}$ and $\mathrm{TiO}_{2} \mathrm{P} 25$ for E. coli inactivation. (Reproduced with permission from reference (103). Copyright 2015 Elsevier.)

In Water Challenges and Solutions on a Global Scale; Loganathan, et al.; ACS Symposium Series; American Chemical Society: Washington, DC, 2015. 
The idea of constructing nanopores in graphene sheets deems it a promising material in the area of water filtration and desalination. The porous materials having narrow distributed pores with a very small pore size ranging between 1-5 $\AA$ are very useful for molecular sieving and separation purposes (104). The ease of fabrication, good mechanical strength and presence of an interlayer separation of approx. $6 \AA$ helps them to accommodate water molecules, and in-turn makes them a good candidate for water purification. Graphene sheets with tiny perforations allow the passage of water molecules but restrict the passage of contaminants and pollutants.

Graphene is an impermeable membrane due to the delocalized $\pi$-orbital cloud (105). The $\pi$-orbital cloud can block the entry of very small molecules such as hydrogen, helium etc. (4) If it is possible to make pores in graphene, while retaining its structural integrity, graphene can be a good material for the purification of gases and liquids. Studies have proven that the water flux through nanoporous graphene is greatly dependent on the diameter and functionalization of the pores (106). The water flow rate through graphene increases with an increase in pore diameter and applied pressure. The incorporation of charged species into graphene pores, either by chemical oxidation or by functionalization, can contribute positively to water desalination (107). Wang and Karnik reported that water permeation through graphene nanopores is based on the principle of reverse osmosis (RO) and the selectivity can be increased by hydrogen functionalization of the graphene pores. Hydroxyl group functionalization increases the speed of water transport (Figure 5) (108).

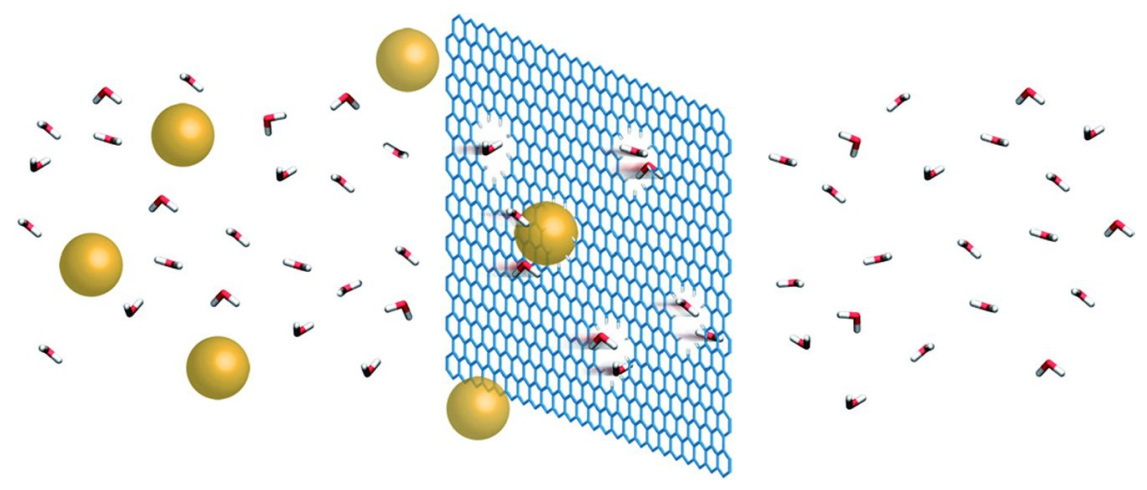

Figure 5. A graphene membrane with subnanometer pores is a promising $R O$ membrane. High pressure applied to the salt water (left) drives water molecules across the graphene membrane (right), while salt ions (spheres) are blocked. (Reproduced with permission from reference (108). Copyright 2012 Nature Publishing Group.)

Sint et al. reported that nanopores functionalized in graphene layers can act as ion sieves of high selectivity (109). The negatively charged fluorine or nitrogen terminated nanopores favor the flow of cations and positively charged hydrogen 
functionalization favors the passage of anions. These nanopores can be generated by ion etching (110) or chemical functionalization. The ion selectivity and passage through the nanopores depend upon the size, shape and the nature of functional groups attached to the pores.

Many theoretical studies have proven that thin layer graphene can act as a superior separation membrane for gases, various ions, water etc. Cohen-Tanugi and Grossman reported that the nanopores in single layer graphene sheets can filter sodium chloride salt from water in an effective way (111). Using classical molecular dynamics they proved that the pore diameter and adequate pore size distribution aid the nanosheet in preventing the passage of salt but permit the flow of water. Also, their studies suggest that the functional groups in the graphene sheets, such as the hydroxyl group, can double the water flux due to its high hydrophilicity. Their work states that atomically thin, periodic nanostructures like graphene, prepared using the bottom up technique, and along with the redesign of desalination membranes, can overcome the drawbacks of current water purification technologies. A schematic representation of the desalination of salt water is shown in Figure 6.

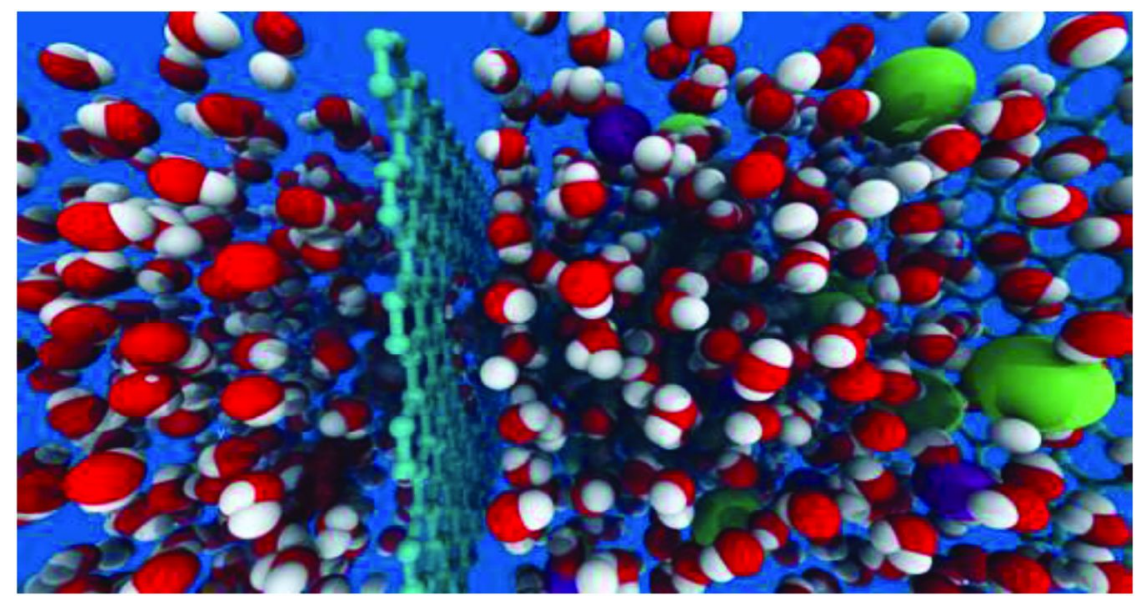

Figure 6. Schematic representation of the desalination of salt water. Right side: Water molecules and sodium and chlorine ions in saltwater. Center: sheet of graphene (pale blue). Left side: water molecules (left side)). (Reproduced with permission from reference (111). Copyright 2012 American Chemical Society.)

R. K. Joshi et al. studied the permeation of water through micrometer thick GO laminates prepared using a vacuum filtration technique (112). The GO laminates act like a molecular sieve which block all solute particles possessing a hydrated diameter greater than $4.5 \AA$. It was claimed that the membrane permeates molecules of lesser size, one thousand times faster than that by simple diffusion and this behavior is due to the network of nanocapillaries in graphene which exerts high pressure on ions inside the pores. 
Ultrafast water permeation membranes of nanostrand channeled GO membranes, possessing nanochannels of a diameter of 3-5 $\mathrm{nm}$ has been reported by Huang et al. (113) As prepared nanostrand GO membranes have ten times higher permeation rate than simple GO membranes and one hundred times higher than that of commercially available ultra-filtration membranes. The authors prepared the nanostrand channeled GO using a multi-step process in which a dispersion of positively charged copper hydroxide nanostrands (CHNs) and negatively charged GO sheets is prepared on a porous support, followed by hydrazine reduction, and finally the CHN is removed by EDTA washing. Recent research studies state that the ultrafast permeation of water through graphene-based nanochannels is possible. Sun et al. studied the permeation of water through graphene nanochannels without external hydrostatic pressures (114). Their research work focused on using an isotope labeling technique to study the water permeation through nanocapallaries and to evaluate the transport properties of solvent water in the presence of dissolved ions. The authors were able to prove that liquid water can undergo an ultrafast permeation through the nanocapillaries in the GO membrane and that the water permeation is lowered when it is mixed with ions. Figure 7 shows the preparation of nanocapillaries on GO membranes using the vacuum filtration technique and the permeation of water through this membrane.

Han et al. fabricated ultrathin graphene membranes with 2D nanochannels having a high water flux of $21.8 \mathrm{~L} \mathrm{~m}^{-2} \mathrm{~h}^{-1} \mathrm{bar}^{-1}$ with the support of PVDF based filtration membranes (115). The membranes showed a high retention rate for dyes but moderate rates for salts. The as prepared membranes demonstrated properties of graphene such as high thermal stability, excellent mechanical properties, and those of PVDF such as high flexibility, processability etc. Similarly, when $\mathrm{GO}$ is blended with polysulfone, it shows high salt rejection rate (116). The hydrophilicity, water flux and salt rejection properties of the membrane were enhanced by increasing the loading content of GO in the polymer matrix. The authors have shown that approx. $72 \%$ of salt rejection (for $1000 \mathrm{ppm}$ sodium sulfate solution) is exhibited by $2000 \mathrm{ppm}$ GO membrane. They also claimed that the rate of salt rejection is dependent upon the $\mathrm{pH}$ of the solution; the higher the $\mathrm{pH}$, the greater the rejection rate.

In many countries contamination of ground water with arsenic, which is considered to be one of the most toxic and carcinogenic elements, has led to mass epidemic diseases. In this context, many researchers are focusing on water filtration technology to reduce the arsenic content in water. Chandra et al. synthesized water dispersible magnetite (M)/RGO composites for the removal of arsenic from ground water. They have chemically synthesized M/RGO composites possessing super paramagnetic properties at room temperature with an average particle size of approx. $10 \mathrm{~nm}$ for magnetite. Based on the adsorption studies, they reported that the removal capacity of As(III) is higher than that of $\mathrm{As}(\mathrm{V})$ with this composite. The composite exhibits nearly $99.9 \%$ arsenic removal from water (117). The presence of humic acid (HA) in natural water will adversely affect the ability to remove arsenic. To overcome this negative influence of $\mathrm{HA}$, Paul et al. synthesized a magnetic nanocomposite of $\mathrm{Fe}_{3} \mathrm{O}_{4}$ and graphene using a co-precipitation technique (118). They claimed that their nanocomposite 
reverses the role of HA to a positive influence, which open up a new graphene nanotechnology for the removal of arsenic from water. The maximum uptake of arsenate and arsenite observed in the presence of RGO-Fe-HA is 16 and $7.5 \mathrm{mg}$ $\mathrm{g}^{-1}$, respectively. This positive observation for the HA present during the removal of arsenic using the $\mathrm{GO}-\mathrm{Fe}_{3} \mathrm{O}_{4}$ nanocomposite materials is not only surprising but also very motivating for the future of nanotechnology in water research. Their work confirmed that the HA coating significantly enhances the arsenic adsorption mechanism through $\pi-\pi$ interactions of aromatic amine groups of humic acid with RGO.

(a)

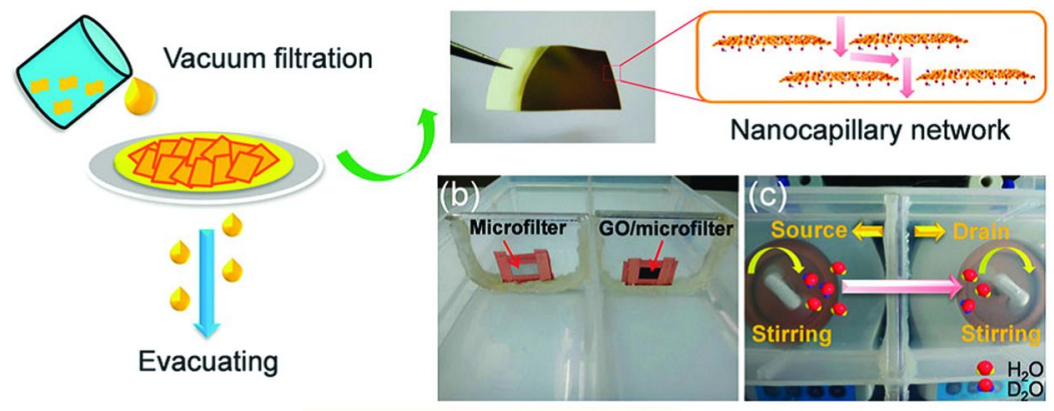

(d)
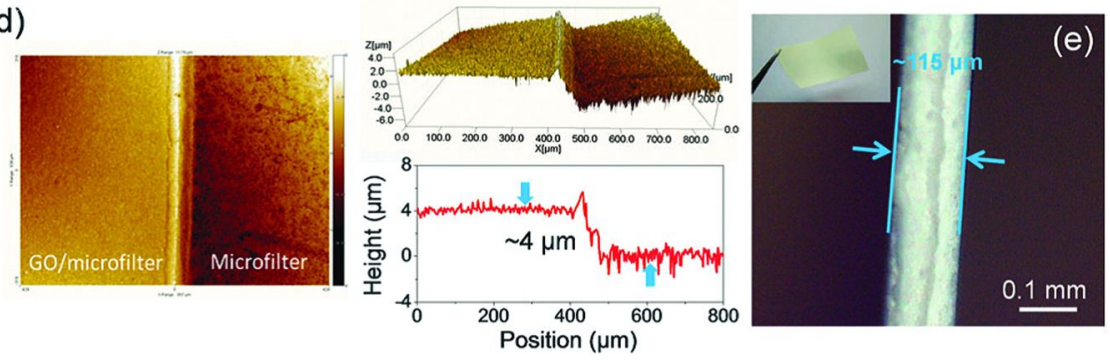

Figure 7. (a) Left panel: schematic drawing of the fabrication of GO membranes using vacuum-filtration. Right panel: a photograph of the as-synthesized GO membrane and a schematic diagram of its cross-sectional structure. $(\boldsymbol{b}, \boldsymbol{c})$ Photographs of the home-made permeation apparatus and the $\mathrm{D}_{2} \mathrm{O}$ labelled water transmembrane permeation process. (d) White light interference characterization for the interface between $G O$ with cellulose membrane and microfilter membranes. (e) An optical image of the cross-section of a cellulose microfilter. The inset shows a photograph of the microfilter used in the experiments. (Reproduced with permission from reference (114). Copyright 2015 Royal Society of Chemistry.)

$\mathrm{Hu}$ and $\mathrm{Mi}$ have synthesized a new water filtration system using GO nanosheets. The nanosheets are fabricated by a layer-by-layer deposition technique, in which the GO layers were cross-linked by using 1,3,5benzenetricarbonyl trichloride on a polydopamine-coated polysulfone support (119). Water can flow through the nanochannels between each GO layers, while the unwanted solute/foreign particles are simultaneously rejected by size exclusion 
and charge effects. The water flux and rejection performance of the as prepared GO membrane was tested using a dead end membrane filtration system and the flux was roughly 4-10 times higher than that of most commercial nanofiltration membranes. They also found that the developed GO membrane exhibited a low rejection of monovalent and divalent salts $(6-46 \%)$, a moderate rejection rate of Methylene Blue (46-66\%) and a high rejection rate of Rhodamine-WT (93-95\%). The main benefit of graphene nanomaterials over other carbon based nanomaterials is its economic advantages; graphene can be produced at a price that is almost negligible cost from inexpensive graphite $(120,121)$.

The antimicrobial properties, fibrous shape, and high conductivity of carbon nanotubes (CNTs) allow for the use of novel CNT filters for the removal of pathogenic bacterial and viral species. The thin layer of CNTs effectively removes bacteria by size exclusion and viruses by depth filtration (122). Iron oxides have been widely used in the environmental field as potential adsorbents due to their redox cycle, ion exchange, high affinity for contaminants and magnetic properties. Additionally, after the removal of the contaminants, magnetic oxides can be recovered from aqueous media, allowing for a more economical, cost-effective cleaning process (123). In relation to environmental remediation, nanomaterials have proven more effective than standard approaches, an advantage attributed to their elevated reactivity and increased surface-to-volume ratio (124). Such technologies reduce the concentration of contaminants to parts per billion (ppb) levels and aid in meeting water quality standards.

Due to advances in the area of desalination and the use of nanomaterials, seawater has become a realistic source of potable water for consumption and industrial use. Indeed, developments in the area of nanotechnology indicates that many of the current issues associated with water quality could be resolved or at least significantly amended using nanocatalysts, nanosorbents, bioactive NPs, nanostructured catalytic membranes and NP enhanced filtration methods. The RO process is used in many desalination plants in order to convert seawater to potable water. This method operates by forcing saltwater under pressure through a membrane, typically a polymer with many nanosize pores, allowing water through the pores but stopping the passage of salts and bacteria. In order to produce desalinated water, the osmotic pressure of the feed water needs to be exceeded. Therefore, RO systems require pumps to maintain sufficient pressure to force the water through the membrane as well as cleaning procedures to clean bacteria that grows on the saltwater side of the membrane. Recent studies focus on the use of nanomaterials to decrease the pressure needed to forcefully pass water through the filter and to reduce the capability of bacteria to colonize the membrane resulting in membrane fouling (125). The preparation of membranes incorporating NPs or nanotubes allows for an interaction between the NP surfaces and the polymer chains, resulting in the formation of desirable structured membranes. These modifications of membrane structure result in favorable selectivity, permeability, and satisfactory performance in ultra-filtration and nano-filtration membranes. Furthermore, it is thought that the hydrophilic properties of the NP functional groups are able to control membrane fouling which is a major drawback of membrane separation technology (126). The use of CNTs for water cleaning has shown great potential due to their capacity to act as an adsorbent substance 
aiding in the elimination of undesirable contaminants of chemical and biological origin. This ability can be attributed to their structural and function properties. Additionally, due to their antimicrobial properties, CNTs possess a remarkable biofouling resistance that is a major advantage for desalination applications (127). Consequently, NPs will allow for the use of more economical materials than those currently available, thereby reducing the financial costs associated with water desalination (128). At present there is an abundance of desalination methods which use nanomaterials as functional components, currently these methods are being developed to market level. CNTs have been evaluated for desalination due to their rapid water transport properties, large surface area and ease of functionalization (124).

\section{Nanomaterials Based Sensors for Water Technologies}

In recent years, the advances in synthesis and functionalization of nanomaterials have allowed the application of these materials as functional probes for the detection of pollutants in water. In this section, the use of metal NPs, quantum dots (QDs) and CNTs for water quality monitoring will be reviewed.

\section{Metal Nanoparticles}

Noble metal NPs have attracted much attention for their potential use in sensing due to their unique optical properties. They exhibit localized surface plasmon resonances (LSPRs) due to the collective oscillation of the conduction electrons of the particle in response to light irradiation (127). This process is illustrated in Figure 8. For noble metal NPs, this phenomenon occurs at specific wavelengths in the visible region. This LSPR is dependent not only on the size, shape and composition of the particles but also upon the separation distance between the particles and the dielectric environment of the surrounding medium (128). Thus, changes in the interparticle distance or changes in the environment at the particle surface can lead to changes in the SPR which can be manifested as a color change that is visible to the naked eye.

For example, Liu et al. developed a gold NP based sensor for lead ions (129). This sensor consisted of $13 \mathrm{~nm}$ gold NPs modified with an oligonucleotide, a DNAzyme (called 17E) and a substrate DNA sequence. The substrate DNA sequence was designed to incorporate regions which hybridize to the DNA sequence on the NPs and a recognition region for the enzyme. In the absence of lead ions, the substrate DNA hybridizes to the DNA on the NPs, leading to aggregation of the NPs and a visible blue color. However, the addition of lead ions results in the hydrolytic cleavage of the substrate DNA sequence by 17E, thus preventing the formation of NP aggregates. Thus, a red color appears as a result. The components of the sensor and the process by which the color change occurs are shown in Figure 9. The color change of the sensor, induced by the presence of lead ions, could be monitored using UV-Vis spectroscopy. It was reported that the non-optimized sensor could detect lead ion concentrations in the range of $0.1-4.0 \mu \mathrm{M}$. 


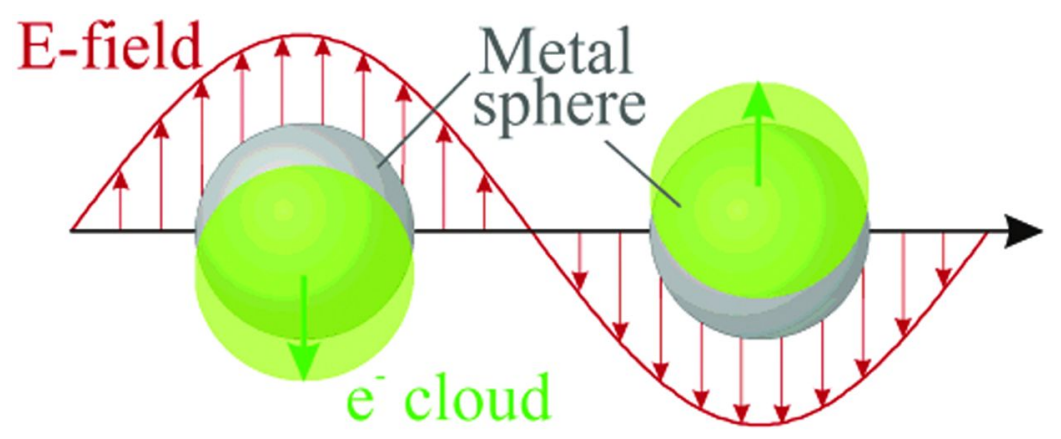

Figure 8. The formation of SPR in a small spherical metallic NP that is irradiated by light. (Reproduced with permission from reference (128). Copyright 2003 American Chemical Society.)

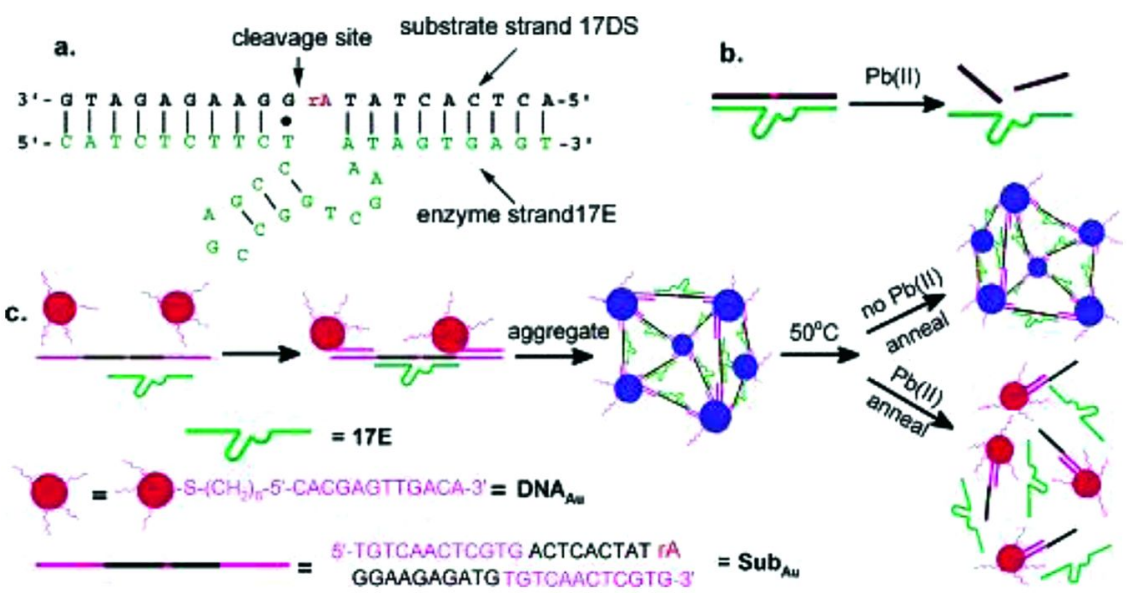

Figure 9. (a) The enzyme system consists of an enzyme strand (17E) and a substrate strand (17DS). Lead ion catalyzed cleavage occurs at the site indicated by a black arrow. Other than a ribonucleosideadenosine at the cleavage site

$(r A)$, all other nucleosides are deoxyribonucleosides. (b) Cleavage of the substrate strand 17DS by the enzyme strand $17 \mathrm{E}$ in the presence of lead ions. (c) DNAzyme-directed assembly of gold NPs. Addition of $\mathrm{Pb}^{2+}$ ions results in the cleavage of the linking DNA strands and the subsequent loss of the NP aggregates. In this system, the 17DS has been extended on both the 3' and 5' ends for 12 bases, to give sequences which are complementary to the oligonucleotides attached to the $13 \mathrm{~nm}$ gold NPs (DNAAu). (Reproduced with permission from reference (129). Copyright 2003 American Chemical Society.) 
A similar methodology was employed by these researchers to develop a gold NP based sensor for copper ions (130). However, to prevent interference in samples resulting from non-specific nucleic acid cleavage, a DNA ligation enzyme was used, rather than a DNA cleavage enzyme. Thus, the presence of copper ion was signaled by the formation of gold NP aggregates, resulting in a color change from red to blue. It was demonstrated that the system was sensitive enough to detect $\mathrm{Cu}^{2+}$ in drinking water, at the limits specified by the U.S. Environmental Protection Agency (EPA) and the WHO i.e. at 20 and $30 \mu \mathrm{M}$ respectively.

Annadhasan et al. reported the use of tyrosine stabilized silver NPs for the colorimetric detection of mercury ions and manganese ions in drinking water (131). The limit of detection for $\mathrm{Hg}^{2+}$ ions was found to be $19 \mathrm{nM}$ and the limit of detection for $\mathrm{Mn}^{2+}$ ions was found to be $23 \mathrm{nM}$. A gold NP based sensor for colorimetric detection of cholera toxin in water was developed by Scholfield et al. (132) The surface of the NPs was functionalized with a lactose derivative. Binding of the cholera toxin to the lactose induced aggregation of the NPs and consequent color change from red to purple. Gold nanorod assemblies were used for the detection of microcystin-LR toxin in water (133). This toxin originates from common blue-green algae. It has been reported that sustained exposure to small concentrations of this toxin in drinking water can cause liver cancer (134). Two types of protein functionalized gold nanorods were prepared which self-assembled into side-by-side or end-to-end assemblies. The addition of the microcystin-LR toxin resulted in disruption of these assemblies and consequently changes in the UV-Vis absorption spectra of the nanorods. Newman et al. reported the use of zirconium phosphate modified gold NPs for the detection of organophosphates (135). The binding of the organophosphate resulted in a blue shift of the SPR of the gold NPs. It was noted that the SPR shift was independent of the organophosphate concentration beyond a threshold concentration of $5 \times$ $10^{-7} \mathrm{M}$ for diethylchlorophosphate. Therefore, this sensor is designed to be a presumptive test for the presence or absence of organophosphate, rather than for quantitative analysis of organophosphate. Anti-E. coli antibody conjugated gold nanorods were used to detect $E$. coli bacteria in water at concentrations of 50 Colony Forming Units $\mathrm{mL}^{-1}$ (136). The detection mechanism was based on the increased two photon Rayleigh scattering observed after addition of $E$. coli bacteria to the NPs. It was reported that this method showed much greater sensitivity ( 2 orders of magnitude more sensitive) than the usual colorimetric techniques, which are typically used. This sensor also had the advantage of offering more rapid results than conventional methods for detection of $E$. coli in water.

The LSPRs of metal NPs can also be exploited for the detection of species of interest by use of surface-enhanced Raman spectroscopy (SERS) and surface-enhanced resonance Raman spectroscopy (SERRS). When Raman scattering molecules are in close proximity to metal NPs, their scattering can be intensely enhanced upon excitation of the NP LSPR. This can result in a Raman signal enhancement of up to $10^{14}$, allowing single molecule detection (137). Cysteine modified gold NPs were used as a SERS probe for the detection of trinitrotoluene (TNT) in water at 2 picomolar concentration (138). SERRS 
has been used for the detection of C. parvum and Giardia lamblia (139). Gold NPs were functionalized with antibodies specific to C. parvum or G. lamblia and further functionalized with Raman active dye molecules. After incubation with the antibody-NP conjugates, C. parvum oocysts and G. lamblia could easily be analyzed using Raman spectroscopy.

Metal NPs can also be used for the electrochemical detection of species in water. A multilayer assembly of polyelectrolyte gold NPs has been used for the detection of arsenic ions which exhibited a limit of detection of $0.48 \mu \mathrm{M}$ (140). Also, a silver NP based electrochemical sensor, used for the detection of nitrite ion, has been developed by Rastogi et al. (141) They reported that this system offered nitrite ion detection over a wide linear range, with a lower limit of detection, higher sensitivity and faster response time than that of other previously reported nitrite sensors.

An enzyme amplified sandwich electrochemical immunosensor, using dual labeled gold NPs (alkaline phosphatase (ALP) and anti-oocysts monoclonal antibody (McAb)) in indium tin oxide (ITO), was used to detect C. parvum (142), as illustrated in Figure 10. Anti-oocysts McAb were immobilized on a $\mathrm{Au}$ NP functionalized ITO electrode. The subsequent binding of analytes and dual labeled gold NP probe resulted in detection of the C. parvum target. This yielded very sensitive detection (a limit of detection of 3 oocysts $\mathrm{mL}^{-1}$ ) in a short processing time.

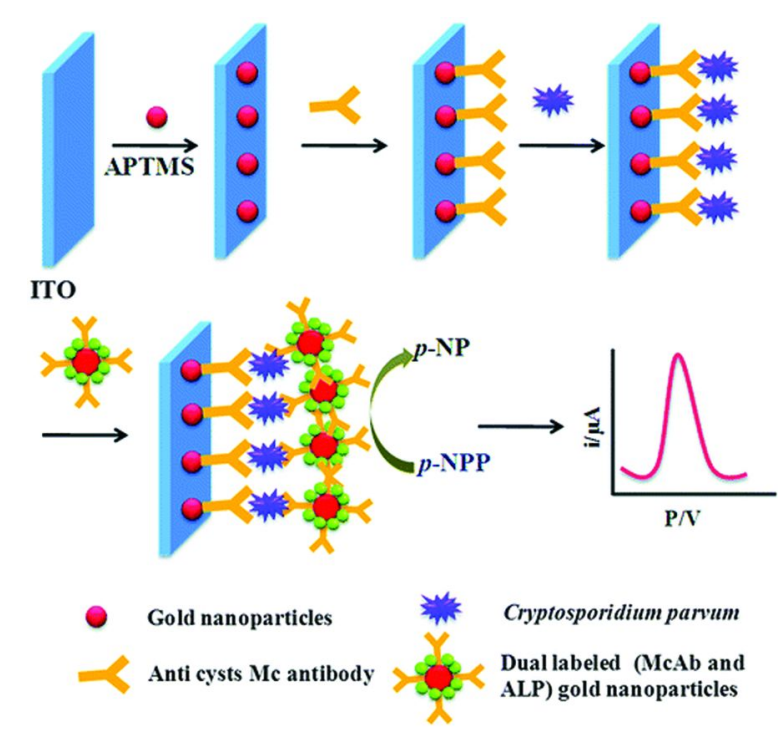

Figure 10. Electrochemical detection of C. parvum using antibody functionalized Au NPs. (Reproduced with permission from reference (142). Copyright 2011 Royal Society of Chemistry.) 


\section{Quantum Dots}

So far, the use of NPs for SPR based sensing and electrochemical detection has been discussed. However, changes in fluorescence intensity can also be exploited for sensing applications. Recent advances in the synthesis of QDs have enabled the development of novel fluorescent probes for the detection of species of interest.

QDs are semiconductor NPs which have emission wavelengths that scale with size. The emission spectrum of QDs has been shown to be ten to twenty times brighter than organic fluorophores (143). Water-soluble mercaptoacetic acid-capped $\mathrm{CdS}$ and $\mathrm{CdS} / \mathrm{ZnS}$ QDs were developed for the fluorescent detection of $\mathrm{Hg}^{2+}$ ions. The presence of the mercury ion was signaled by the fluorescence quenching of the QDs which was shown to be linearly proportional to the mercury ion concentration. Limits of detection in the nanomolar range were reported for these sensors (144). However, due to concerns related to the potential toxicity of cadmium, a modified mercury sensor was developed. $\mathrm{N}$-acetyl-cysteine coated zinc sulfide NPs were prepared by a one-step synthetic method in an aqueous medium (145). These NPs were used for the trace detection of $\mathrm{Hg}^{2+}$ ions in water, yielding a limit of detection of $5 \mathrm{nM}$.

Similarly, gluthathione-capped ZnSe QDs were prepared and used for the determination of lead ions (146). This system demonstrated improved sensitivity and selectivity for the detection of trace $\mathrm{Pb}^{2+}$ in water, such that a detection limit of $0.71 \mathrm{nM}$ was achieved. The U.S. EPA stipulates that the maximum level of lead allowed in drinking water is $72 \mathrm{nM}(15 \mathrm{ppb})$ (147). Therefore this nanosensor could be used to ensure compliance with this level. In a method similar to the strategy of Liu et al. $(129,130)$, a QD-DNAzyme sensor for the detection of $\mathrm{Pb}^{2+}$ and $\mathrm{Cu}^{2+}$ ions has been reported (148). Quencher-labeled DNAzymes were synthesised and attached to the surface of CdSe/ZnS QDs. Since the quencher molecule was close to the NP surface, the QD fluorescence of the QD was quenched. However, the addition of lead ions resulted in cleavage of the quencher-labeled DNAzymes from the QD and resultant restoration of the QD fluorescence. Using this strategy, it was also possible to simultaneously detect lead and copper ions using two different colors of QDs, with minimal cross talk between the $\mathrm{Pb}^{2+}$ detection and $\mathrm{Cu}^{2+}$ detection. The limits of detection of 0.2 and $0.5 \mathrm{nM}$ were reported for $\mathrm{Pb}^{2+}$ and $\mathrm{Cu}^{2+}$, respectively.

While using flow cytometry, Hahn et al. reported that the use of CdSe/ZnS core/shell bioconjugates, resulted in increased fluorescence intensities, lower limits of detection and improved accuracy when analyzing a mixture of pathogenic E. coli $\mathrm{O} 157: \mathrm{H} 7$ and harmless $E$. coli $\mathrm{DH} 5 \alpha$, when compared to results using a green organic dye (149).

Agrawal et al. used a QD-magnetic NP based sensor for the detection of the waterborne pathogens E. coli and Salmonella typhimurium (150). Firstly, they prepared magnetic NPs tagged with anti-E. coli and anti-S. typhimurium antibodies. They also prepared green fluorescent cadmium telluride QDs tagged with anti-E. coli antibodies and red fluorescent QDs tagged with anti-S. typhimurium antibodies. The antibody-tagged magnetic NPs were injected into microchannels that were preloaded with bacterial samples and also a solution of antibody-tagged QDs. Removal of the magnets from the pre-capture zone 
allowed the flow of the antibody-tagged magnetic NPs towards the capture zone, along the flow of bacterial samples. Removal of the magnets from capture zone caused the antibody-tagged QDs to flow. In the detection zone, QDs, bacterial samples and magnetic NPs formed a complex that fluoresced when irradiated with visible light.

\section{Carbon Nanotubes and Graphene}

The unique electrical properties and high surface area of CNTs have been exploited for the detection of a wide variety of water pollutants. For example, an electrode array composed of CNTs and coated with a bismuth film was used for the voltammetric detection of cadmium(II) and lead(II) at concentrations below the ppb level (151). A limit of detection of $0.04 \mu \mathrm{g} \mathrm{L}^{-1}$ was reported. Cysteine coated CNTs were used in the construction of an electrochemical sensor for the simultaneous detection of lead and copper ions (152). Detection limits of $1 \mathrm{ppb}$ and $15 \mathrm{ppb}$ were reported for $\mathrm{Pb}^{2+}$ and $\mathrm{Cu}^{2+}$ respectively. This sensor was deployed for the determination of $\mathrm{Pb}^{2+}$ and $\mathrm{Cu}^{2+}$ in spiked lake water samples. Average recoveries of $96.2 \%$ and $94.5 \%$ were reported for $\mathrm{Pb}^{2+}$ and $\mathrm{Cu}^{2+}$ respectively. Organophosphate pesticides have been detected using self-assembled layers of acetylcholinesterase immobilized on a CNT modified glassy carbon electrode (153). Single walled CNTs and antibodies have been combined to create a paper based sensor for the detection of microcystin-LR toxin (154). This nanosensor achieved a limit of detection of $0.6 \mathrm{ppb}$ with a response time that was 28 times quicker than that obtained using an enzyme linked immunosorbent assay. A CNT based electrochemical biosensor, for the detection of bacteriophage MS2, was recently reported by Prieto-Simon et al. (155) This virus is often detected in sewage impacted water supplies. Excellent sensitivity and limit of detection $\left(9.3\right.$ and $9.8 \mathrm{pfu} \mathrm{mL}^{-1}$ in buffer and in river water, respectively) were achieved using this sensor.

Another allotrope of carbon; graphene, has been used for the development of sensors for water contaminants. Even though it was only first produced in the laboratory in 2003 (156), graphene based sensors have since been utilized for the detection of heavy metals, pathogenic bacteria and organic pollutants. The reason for the intense interest in graphene lies in its unique physical and chemical properties: high surface area (theoretically $2630 \mathrm{~m}^{2} \mathrm{~g}^{-1}$ for single-layer graphene) (101), superior thermal conductivity (157) and electric conductivity (158), and excellent mechanical strength (159).

A nanocomposite of graphene sheets modified with Nafion was used for the detection of cadmium ions using differential pulse anodic stripping voltammetry (160). This system provided detection of $\mathrm{Cd}^{2+}$ in the range of $0.25-5.00 \mu \mathrm{g} \mathrm{L}^{-1}$, with a limit of detection of $3.50 \mu \mathrm{g} \mathrm{L}-1$. Additionally, the sensor could differentiate between cadmium ions and interferents such as magnesium and zinc salts. This sensor was deemed to offer several advantages compared to existing methods for cadmium analysis, namely that it was more cost effective, portable and reliable and more suited to on-site detection. A copper NP -GO hybrid was used for 
the electrochemical detection of 2-naphthol in river water (161). 2-naphthol is widely used in the syntheses of azo-dyes, rubber antioxidants, bactericides, mildew preventives and antiseptic substances. The sensor was successfully used to detect 2-naphthol in the linear ranges of 0.1-4.0 $\mu \mathrm{M}$ and 4.0-130 $\mu \mathrm{M}$, with a limit of detection of $5.0 \mathrm{nM}$. An electrochemical sensor for the simultaneous detection of nitrite and sulfite in water was prepared using potassium doped graphene (162). The sensor showed excellent sensitivity and selectivity towards nitrite and sulfite and superior antifouling properties compared to other systems developed for this purpose.

While the majority of graphene based sensors employ electrochemical detection methods, a graphene based fluorescent nanoprobe for detection of silver ions has also been developed (163). Fluorescein labeled silver specific oligonucleotides (SSO) were prepared. In the absence of silver ions, the DNA sequence exists as a flexible single strand. The addition of silver ions results in the formation of a complex between the Ag and the cytosine bases of the oligonucleotide. This induces the formation of an inflexible hairpin structure. GO is added to selectively adsorb the unbound oligonucleotides and quench their emission. The silver ions complexed with the DNA are not adsorbed and thus, their fluorescence is not quenched. A schematic illustration of the sensor is shown in Figure 11. It was demonstrated that this sensor could differentiate silver ions in the presence of twelve other interferent metal ions, present at tenfold higher concentration.

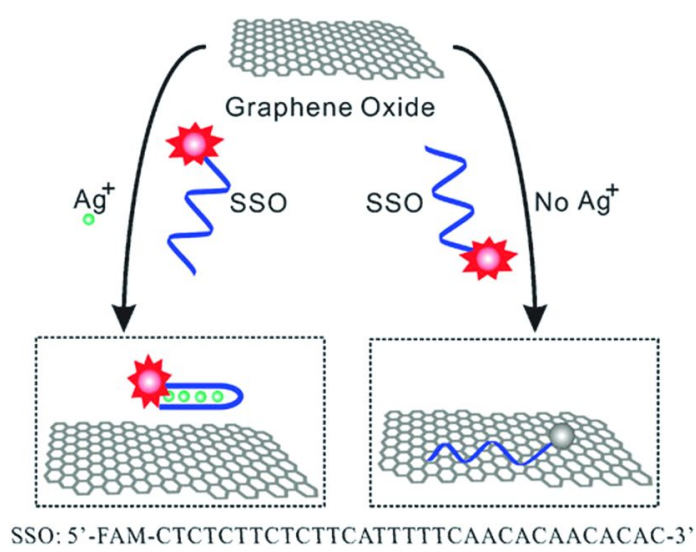

Figure 11. Diagram of a fluorescent sensor for silver ions. In the presence of $\mathrm{Ag}(I)$ the fluorescein labelled oligonucleotides retain their fluorescence. In the absence of silver ion, the oligonucleotides are adsorbed onto graphene and their emission is quenched. (Reproduced with permission from reference (163).

Copyright 2010 Royal Society of Chemistry.) 


\section{Conclusions}

The provision of safe drinking water is a basic right of all individuals, yet people face genuine issues relating to the availability of a sufficient supply of safe and clean water, affecting their health and economic well-being. Providing a supply of clean safe water economically, is beyond the capacity of current water treatment methods. It is estimated that there are 748 million people throughout the world without access to improved water sources for drinking and many more rely on water that is not safe to consume due to contamination with pathogenic microorganisms. Furthermore, standard water treatment methods show little specificity towards contaminants; filtration (micro, nano and ultra) which leads to the requirement for the extreme use of resources and the elimination of non-harmful components (1). Additionally, this can lead to the formation of residuals/by-products which requires further processing and disposal. The reuse of wastewater is also becoming more and more important due to water scarcity throughout the globe, and it is vitally important for safety reasons to ensure that water for reuse is free from pathogenic microorganisms, particularly if used for food-crop irrigation.

Solar energy is free and ubiquitous on the Earth's surface. The utilization of solar energy for the disinfection of water is a very important area for research and development. Solar irradiation of water can result in the inactivation of pathogenic microorganisms in water due to a combination of UV and thermal effects. Nevertheless, solar disinfection alone may be slow or ineffective against different microorganisms. The addition of a photocatalyst, such as titanium dioxide, can dramatically enhance the solar disinfection of water. The photocatalytic mechanism is non-specific through the production of ROS which reduces the likelihood of resistance being developed. In order to improve upon the solar efficiency of photocatalytic disinfection, many researchers are investigating novel visible light active photocatalytic materials which can utilise more of the solar spectrum.

The study of NPs and their applications in science has become a rapidly growing sector of research and development. As the issues with supplying safe potable water are becoming increasingly evident, nanotechnology has been identified as a possible solution to this global problem. Disinfection procedures are a very significant final step in the treatment of both water and wastewater. The antimicrobial nature of some nanomaterials means that they may serve as disinfectants for water treatment, allowing for a reduction in the formation of the disinfection by-products commonly associated with chemical use. In comparison with microsized counterparts, NPs show a significantly higher catalytic activity in catalytic ozonation, photo-Fenton, and Fenton-like reaction, which would improve the reaction efficiency for water decontamination. The important feature of nanocatalysts is that their surface properties can deviate significantly from those of their macroscopic counterparts, as they can reach or penetrate into zones that are inaccessible to microsized solid catalysts. Research on novel nanocatalysts applied in heterogeneous AOPs for the degradation of emerging contaminants in water treatment is currently a very active field. A wide variety of nanomaterial based sensors for the monitoring of water quality have been 
developed. These novel systems offer increased sensitivity, more rapid results and more cost effective solutions when compared with existing analytical methods. However, the suitability and robustness of all these systems under environmental conditions have not yet been established. Further work will be required to address issues such as NP stability and aggregation before such sensors can be deployed within existing water quality monitoring operations. In addition, regardless of their huge potential, the use of nanomaterials does pose some issues, such as the high cost of various nanomaterials, with the exception of $\mathrm{TiO}_{2}$ and polymeric nanofibres. This has led to the concept of retaining and reusing nanomaterials and to the use of low purity nanomaterials, as significant costs are related to obtaining high levels of purity. Nonetheless, the rapid growth and continued advances in the area of nanomaterial based devices for water disinfection and sensing offer great promise for the challenges posed by the water quality issues.

\section{Acknowledgments}

The authors wish to acknowledge financial support under the U.S.-Ireland R\&D Partnership programme from the Science Foundation Ireland (SFI-grant number 10/US/I1822(T)) and U.S. National Science Foundation-CBET (Award 1033317). D. D. Dionysiou also acknowledges support from the University of Cincinnati through a UNESCO co-Chair Professor position on "Water Access and Sustainability". All authors have contributed equally.

\section{References}

1. Das, R.; Hamid, A. B. S.; Ali, E.; Ismail, F. A.; Annuar, M. S. M.; Ramakrishn, S. Multifunctional carbon nanotubes in water treatment: The present, past and future. Desalination 2014, 354, 160-179.

2. WHO and UNICEF 2014, Progress on Sanitation and Drinking Water: 2014 Update; World Health Organization; UNICEF: Geneva, Switzerland, 2014.

3. Bartram, J.; Lewis, K.; Lenton, R.; Wright, A. Focusing on improved water and sanitation for health. Millennium project. Lancet 2005, 365, 810-812.

4. Koenig, S. P.; Wang, L.; Pellegrino, J.; Bunch, S. J. Selective molecular sieving through porous graphene. Nat. Nanotechnol. 2012, 7, 728-732.

5. Berry, V. Impermeability of graphene and its applications. Carbon 2013, 62, $1-10$.

6. Keane, D. A.; McGuigan, K. G.; Fernández-Ibáñez, P.; Polo-López, M. I.; Byrne, J. A.; Dunlop, P. S. M.; O’Shea, K. E.; Dionysiou, D. D.; Pillai, S. C. Solar catalysis for water disinfection: materials and reactor design. Catal. Sci. Technol. 2014, 4, 1211-1226.

7. Matsunaga, T.; Tomoda, R.; Nakajima, T.; Wake, H. Photoelectrochemical sterilization of microbial cells by semiconductor powders. FEMS Microbiol. Lett. 1985, 29, 211-214.

8. Dunlop, P. S. M.; Byrne, J. A.; Manga, N.; Eggins, B. R. The photocatalytic removal of bacterial pollutants from drinking water. J. Photochem. Photobiol., A 2002, 148, 355-363. 
9. Dunlop, P. S. M.; Sheeran, C. P.; Byrne, J. A.; McMahon, M. A. S.; Boyle, M. A.; McGuigan, K. G. Inactivation of clinically relevant pathogens by photocatalytic coatings. J. Photochem. Photobiol., A 2010, 216, 303-310.

10. Dunlop, P. S. M.; McMurray, T. A.; Hamilton, J. W. J.; Byrne, J. A. Photocatalytic inactivation of Clostridium perfringens spores on $\mathrm{TiO}_{2}$ electrodes. J. Photochem. Photobiol., A 2008, 196, 113-119.

11. Watts, R. J.; Kong, S.; Orr, M. P.; Miller, G. C.; Henry, B. E. Photocatalytic inactivation of coliform bacteria and viruses in secondary wastewater effluent. Water Res. 1995, 29, 95-100.

12. Sunnotel, O.; Verdoold, R.; Dunlop, P. S. M.; Snelling, W. J.; Lowery, C. J.; Dooley, J. S. G.; Moore, J. E.; Byrne, J. A. Photocatalytic inactivation of cryptosporidium parvum on nanostructured titanium dioxide films. J. Water Health 2010, 8, 83-91.

13. Sichel, C.; de Cara, M.; Tello, J.; Blanco, J.; Fernández-Ibánez, P. Solar photocatalytic disinfection of agricultural pathogenic fungi: Fusarium species. Appl. Catal., B. 2007, 74, 152-160.

14. Linkous, C. A.; Carter, G. J.; Locuson, D. B.; Ouellette, A. J.; Slattery, D. K.; Smith, L. A. Photocatalytic Inhibition of Algae Growth Using $\mathrm{TiO}_{2}, \mathrm{WO}_{3}$, and Cocatalyst Modifications. Environ. Sci. Technol. 2000, 34, 4754-4758.

15. Byrne, J. A.; Fernandez-Ibanez, P. A.; Dunlop, P. S. M.; Alrousan, D. M. A.; Hamilton, J. W. J. Photocatalytic Enhancement for Solar Disinfection of Water: A Review. Int. J. Photoenergy 2011 Article Number: 798051.

16. McCullagh, C.; Robertson, J. M.; Bahnemann, D. W.; Robertson, P. J. K. Res. Chem. Intermed. 2007, 33, 359-375.

17. Malato, S.; Fernandez-Ibanez, P.; Maldonado, M. I.; Blanco, J.; Gernjak, W. Decontamination and disinfection of water by solar photocatalysis: Recent overview and trends. Catal. Today 2009, 147, 1-59.

18. Robertson, P. K. J.; Robertson, J. M. C.; Bahnemann, D. W. Removal of microorganisms and their chemical metabolites from water using photocatalysis. J. Hazard. Mater. 2012, 211, 161-171.

19. Dalrymple, O. K.; Stefanakos, E.; Trotz, M. A.; Goswami, D. Y. A review of mechanisms and modeling of photocatalytic disinfection. Appl. Catal., B 2010, 98, 27-38.

20. Cho, M.; Chung, H.; Choi, W.; Yoon, J. Linear correlation between inactivation of $E$. coli and $\mathrm{OH}$ radical concentration in $\mathrm{TiO}_{2}$ photocatalytic disinfection. Water Res. 2004, 38, 1069-1077.

21. Babuponnusami, A.; Muthukumar, K. A review on Fenton and improvements to the Fenton process for wastewater treatment. J. Environ. Chem. Eng. 2014, 2, 557-572.

22. Bokare, A. D.; Choi, W. Review of iron-free Fenton-like systems for activating $\mathrm{H}_{2} \mathrm{O}_{2}$ in advanced oxidation processes. J. Hazard. Mater. 2014, $275,121-135$.

23. Garrido-Ramírez, E. G.; Theng, B. K. G.; Mora, M. L. Clays and oxide minerals as catalysts and nanocatalysts in Fenton-like reactions - A review. Appl. Clay Sci. 2010, 47, 182-192.

24. Zhao, C.; Zhou, Y.; Ridder, D. J. D.; Zhai, J.; Wei, Y.; Deng, H. Advantages of $\mathrm{TiO}_{2} / 5 \mathrm{~A}$ composite catalyst for photocatalytic degradation of antibiotic 
oxytetracycline in aqueous solution: Comparison between $\mathrm{TiO}_{2}$ and $\mathrm{TiO}_{2} / 5 \mathrm{~A}$ composite system. Chem. Eng. J. 2014, 248, 280-289.

25. Oller, I.; Malato, S.; Sánchez-Pérez, J. A. Combination of Advanced Oxidation Processes and biological treatments for wastewater decontamination - A review. Sci. Total Environ. 2011, 409, 4141-4166.

26. Antoniou, M. G.; Nambiar, U.; Dionysiou, D. D. Investigation of the photocatalytic degradation pathway of the urine metabolite, creatinine: The effect of pH. Water Res. 2009, 43, 3956-3963.

27. Rubio-Clemente, A.; Torres-Palma, R. A.; Peñuela, G. A. Removal of polycyclic aromatic hydrocarbons in aqueous environment by chemical treatments: A review. Sci. Total Environ. 2014, 478, 201-225.

28. Soon, A. N.; Hameed, B. H. Heterogeneous catalytic treatment of synthetic dyes in aqueous media using Fenton and photo-assisted Fenton process. Desalination 2011, 269, 1-16.

29. Sheydaei, M.; Aber, S.; Khataee, A. Preparation of a novel $\gamma$-FeOOH-GAC nano composite for decolorization of textile wastewater by photo Fentonlike process in a continuous reactor. J. Mol. Catal. A: Chem. 2014, 392, 229-234.

30. Zhao, C.; Pelaez, M.; Duan, X.; Deng, H.; O’Shea, K.; Fatta-Kassinos, D.; Dionysiou, D. D. Role of $\mathrm{pH}$ on photolytic and photocatalytic degradation of antibiotic oxytetracycline in aqueous solution under visible/solar light: Kinetics and mechanism studies. Appl. Catal., B 2013, 134-135, 83-92.

31. Sun, S.; Zeng, X.; Lemley, A. T. Nano-magnetite catalyzed heterogeneous Fenton-like degradation of emerging contaminants carbamazepine and ibuprofen in aqueous suspensions and montmorillonite clay slurries at neutral pH. J. Mol. Catal. A: Chem. 2013, 371, 94-103.

32. Oller, I.; Malato, S.; Sánchez-Pérez, J. A.; Maldonado, M. I.; Gassó, R. Detoxification of wastewater containing five common pesticides by solar AOPs-biological coupled system. Catal. Today 2007, 129, 69-78.

33. Moreira, F. C.; Vilar, V. J. P.; Ferreira, A. C. C.; Dos Santos, F. R. A.; Dezotti, M.; Sousa, M. A.; Gonçalves, C.; Boaventura, R. A. R.; Alpendurada, M. F. Treatment of a pesticide-containing wastewater using combined biological and solar-driven AOPs at pilot scale. Chem. Eng. J. 2012, 209, 429-441.

34. Rocha, E. M. R.; Vilar, V. J. P.; Fonseca, A.; Saraiva, I.; Boaventura, R. A. R. Landfill leachate treatment by solar-driven AOPs. Sol. Energy 2011, 85, 46-56.

35. Primo, O.; Rivero, M. J.; Ortiz, I. Photo-Fenton process as an efficient alternative to the treatment of landfill leachates. J. Hazard. Mater. 2008, $153,834-842$.

36. Ayoub, K.; van Hullebusch, E. D.; Cassir, M.; Bermond, A. Application of advanced oxidation processes for TNT removal: A review. J. Hazard. Mater. 2010, 178, 10-28.

37. Ayoub, K.; Nélieu, S.; van Hullebusch, E. D.; Labanowski, J.; SchmitzAfonso, I.; Bermond, A.; Cassir, M. Electro-Fenton removal of TNT: Evidences of the electro-chemical reduction contribution. Appl. Catal., B 2011, 104, 169-176. 
38. Liou, M.; Lu, M.; Chen, J. Oxidation of TNT by photo-Fenton process. Chemosphere 2004, 57, 1107-1114.

39. Tawabini, B.; Zubair, A. Bromate control in phenol-contaminated water treated by UV and ozone processes. Desalination 2011, 267, 16-19.

40. Gimeno, O.; Carbajo, M.; Beltrán, F. J.; Rivas, F. J. Phenol and substituted phenols AOPs remediation. J. Hazard. Mater. 2005, 119, 99-108.

41. Agulló-Barceló, M.; Polo-López, M. I.; Lucena, F.; Jofre, J.; FernándezIbáñez, P. Solar Advanced Oxidation Processes as disinfection tertiary treatments for real wastewater: Implications for water reclamation. Appl. Catal., B 2013, 136-137, 341-350.

42. Bell, A. T. The impact of nanoscience on heterogeneous catalysis. Science 2003, 299, 1688-1691.

43. Nurmi, J. T.; Tratnyek, P. G.; Sarathy, V.; Sarathy, V.; Baer, D. R.; Amonette, J. E.; Pecher, K.; Wang, C.; Linehan, J. C.; Matson, D. W.; Penn, R. L.; Driessen, M. D. Characterization and properties of metallic iron nanoparticles: spectroscopy, electrochemistry, and kinetics. Environ. Sci. Technol. 2005, 39, 1221-1230.

44. Agustina, T. E.; Ang, H. M.; Vareek, V. K. A review of synergistic effect of photocatalysis and ozonation on wastewater treatment. J. Photochem. Photobiol., C 2005, 6, 264-273.

45. Miao, H.; Qin, F.; Tao, G.; Tao, W.; Ruan, W. Detoxification and degradation of microcystin-LR and -RR by ozonation. Chemosphere 2010, 79, 355-361.

46. Ternes, T. A.; Stüber, J.; Herrmann, N.; McDowell, D.; Ried, A.; Kampmann, M.; Teiser, B. Ozonation: a tool for removal of pharmaceuticals, contrast media and musk fragrances from wastewater? Water Res. 2003, 37, 1976-1982.

47. von Gunten, U. Ozonation of drinking water: Part I. Oxidation kinetics and product formation. Water Res. 2003, 37, 1443-1467.

48. Kasprzyk-Hordern, B.; Ziółek, M.; Nawrocki, J. Catalytic ozonation and methods of enhancing molecular ozone reactions in water treatment. Appl. Catal., B 2003, 46, 639-669.

49. Nawrocki, J.; Kasprzyk-Hordern, B. The efficiency and mechanisms of catalytic ozonation. Appl. Catal., B 2010, 99, 27-42.

50. Yang, Y.; Ma, J.; Qin, Q.; Zhai, X. Degradation of nitrobenzene by nano- $\mathrm{TiO}_{2}$ catalyzed ozonation. J. Mol. Catal. A: Chem. 2007, 267, 41-48.

51. Tabatabaei, S. M.; Mehrizad, A.; Gharbani, P. Nano-Catalytic Ozonation of 4-Nitrochlorobenzene in Aqueous Solutions. Eur.-J. Chem. 2012, 9, 1968-1975.

52. Huang, W.; Fang, G.; Wang, C. A nanometer-ZnO catalyst to enhance the ozonation of 2,4,6-trichlorophenol in water. Colloids Surf., A 2005, 260, $45-51$.

53. Dong, Y.; Wang, G.; Jiang, P.; Zhang, A.; Yue, L.; Zhang, X. Catalytic Ozonation of Phenol in Aqueous Solution by $\mathrm{Co}_{3} \mathrm{O}_{4}$ Nanoparticles. Bull. Korean Chem. Soc. 2010, 31, 2830-2834.

54. Zhao, H.; Dong, Y.; Jiang, P.; Wang, G.; Zhang, J.; Li, K. An insight into the kinetics and interface sensitivity for catalytic ozonation: the case of nanosized $\mathrm{NiFe}_{2} \mathrm{O}_{4}$. Catal. Sci. Technol. 2014, 4, 494-501. 
55. Qi, F.; Xu, B.; Chu, W. Heterogeneous catalytic ozonation of phenacetin in water using magnetic spinel ferrite as catalyst: Comparison of surface property and efficiency. J. Mol. Catal. A: Chem. 2015, 396, 164-173.

56. Shahamat, Y. D.; Farzadkia, M.; Nasseri, S.; Mahvi, A. H.; Gholami, M.; Esrafili, A. Magnetic heterogeneous catalytic ozonation: a new removal method for phenol in industrial wastewater. J. Environ. Health. Sci. Eng. 2014, 12, 1-12.

57. Park, H.; Kim, J.; Jung, H.; Seo, J.; Choi, H. Iron Oxide NanoparticleImpregnated Alumina for Catalytic Ozonation of para-Chlorobenzoic Acid in Aqueous Solution. Water, Air, Soil Pollut. 2014, 225 DOI-10.1007/ s11270-014-1975-0.

58. Choi, K.; Lee, W. Enhanced degradation of trichloroethylene in nano-scale zero-valent iron Fenton system with $\mathrm{Cu}$ (II). J. Hazard. Mater. 2012, 211-212, 146-153.

59. Cihanoğlu, A.; Gündüz, G.; Dükkancı, M. Degradation of acetic acid by heterogeneous Fenton-like oxidation over iron-containing ZSM-5 zeolites. Appl. Catal., B 2015, 165, 687-699.

60. Feng, J.; Hu, X.; Yue, P. L. Degradation of salicylic acid by photo-assisted Fenton reaction using $\mathrm{Fe}$ ions on strongly acidic ion exchange resin as catalyst. Chem. Eng. J. 2004, 100, 159-165.

61. Liou, R.; Chen, S.; Hung, M.; Hsu, C.; Lai, J. Fe (III) supported on resin as effective catalyst for the heterogeneous oxidation of phenol in aqueous solution. Chemosphere 2005, 59, 117-125.

62. Duan, F.; Yang, Y.; Li, Y.; Cao, H.; Wang, Y.; Zhang, Y. Heterogeneous Fenton-like degradation of 4-chlorophenol using iron/ordered mesoporous carbon catalyst. J. Environ. Sci. 2014, 26, 1171-1179.

63. Subbaramaiah, P. V.; Srivastava, V. C.; Mall, I. D. Catalytic oxidation of nitrobenzene by copper loaded activated carbon. Sep. Purif. Technol. 2014, 125, 284-290.

64. Kitis, M.; Kaplan, S. S. Advanced oxidation of natural organic matter using hydrogen peroxide and iron-coated pumice particles. Chemosphere 2007, 68, 1846-1853.

65. Pouran, S. R.; Abdul Aziz, A. R.; Wan Daud, W. M. A. Review on the main advances in photo-Fenton oxidation system for recalcitrant wastewaters. $J$. Ind. Eng. Chem. 2015, 21, 53-69.

66. Ortiz De La Plata, G. B.; Alfano, O. M.; Cassano, A. E. 2-Chlorophenol degradation via photo Fenton reaction employing zero valent iron nanoparticles. J. Photochem. Photobiol., A 2012, 233, 53-59.

67. Vinita, M.; Praveena Juliya Dorathi, R.; Palanivelu, K. Degradation of 2,4,6trichlorophenol by photo Fenton's like method using nano heterogeneous catalytic ferric ion. Sol. Energy 2010, 84, 1613-1618.

68. Li, W.; Wang, Y.; Irini, A. Effect of $\mathrm{pH}$ and $\mathrm{H}_{2} \mathrm{O}_{2}$ dosage on catechol oxidation in nano- $\mathrm{Fe}_{3} \mathrm{O}_{4}$ catalyzing $\mathrm{UV}-\mathrm{Fenton}$ and identification of reactive oxygen species. Chem. Eng. J. 2014, 244, 1-8.

69. Sze Nga Sum, O.; Feng, J.; Hu, X.; Lock Yue, P. Pillared laponite clay-based $\mathrm{Fe}$ nanocomposites as heterogeneous catalysts for photo-Fenton degradation of acid black 1. Chem. Eng. Sci. 2004, 59, 5269-5275. 
70. Guo, S.; Zhang, G.; Yu, J. C. Enhanced photo-Fenton degradation of rhodamine $\mathrm{B}$ using graphene oxide-amorphous $\mathrm{FePO}_{4}$ as effective and stable heterogeneous catalyst. J. Colloid Interface Sci. 2015, 448, 460-466.

71. Zhao, H.; Cao, J.; Lv, H.; Wang, Y.; Zhao, G. 3D nano-scale perovskitebased composite as Fenton-like system for efficient oxidative degradation of ketoprofen. Catal. Commun. 2013, 41, 87-90.

72. Zeng, X.; Hanna, K.; Lemley, A. T. Cathodic Fenton degradation of 4,6dinitro-o-cresol with nano-magnetite. J. Mol. Catal. A: Chem. 2011, 339, $1-7$.

73. Sun, S-P.; Zeng, X.; Li, C.; Lemley, A. T. Enhanced heterogeneous and homogeneous Fenton-like degradation of carbamazepine by nano- $\mathrm{Fe}_{3} \mathrm{O}_{4} / \mathrm{H}_{2} \mathrm{O}_{2}$ with nitrilotriacetic acid. Chem. Eng. J. 2014, 244, 44-49.

74. Kurian, M.; Nair, D. S. Heterogeneous Fenton behavior of nano nickel zinc ferrite catalysts in the degradation of 4-chlorophenol from water under neutral conditions. J. Water Process. Eng. 2015 DOI:10.1016/j.jwpe.2014.10.011.

75. Banerjee, S.; Pillai, S. C.; Falaras, P.; O’Shea, K. E.; Byrne, J. A.; Dionysiou, D. D. New Insights in to the Mechanism of Visible Light Photocatalysis. J. Phys. Chem. Lett. 2014, 5, 2543-2554.

76. Khalil, A.; Gondal, M. A.; Dastageer, M. A. Augmented photocatalytic activity of palladium incorporated $\mathrm{ZnO}$ nanoparticles in the disinfection of Escerichia coli microorganism from water. Appl. Catal., A 2011, 402, 162-167.

77. Karunakaran, C.; Gomathisankar, P.; Manikandan, G. Preparation and characterization of antimicrobial Ce-doped $\mathrm{ZnO}$ nanoparticles for photocatalytic detoxification of cyanide. Mater. Chem. Phys. 2010, 123, 585-594.

78. Fisher, M. B.; Keane, D. A; Fernández-Ibáñez, P.; Colreavy, J.; Hinder, S. J.; McGuigan, K. G.; Pillai, S. C. Nitrogen and copper doped solar light active $\mathrm{TiO}_{2}$ photocatalyts for water decontamination. Appl. Catal., B 2013, 130-131, 8-13.

79. Karunakaran, C.; Rajeswari, V.; Gomathisankar, P. Enhanced photocatalytic and antibacterial activities of sol-gel synthesized $\mathrm{ZnO}$ and $\mathrm{Ag}-\mathrm{ZnO}$. Mater. Sci. Semicond. Process. 2011, 14, 133-138.

80. Karunakaran, C.; Rajeswari, V.; Gomathisankar, P. Combustion synthesis of $\mathrm{ZnO}$ and $\mathrm{Ag}$-doped $\mathrm{ZnO}$ and their bactericidal and photocatalytic activities. Superlattices Microstruct. 2011, 50, 234-241.

81. Karunakaran, C.; Rajeswari, V.; Gomathisankar, P. Optical, electricalc photocatalytic, and bactericidal properties of microwave synthesized nanocrystalline Ag-ZnO and ZnO. Solid State Sci. 2011, 13, 923-928.

82. Hamilton, J. W. J.; Byrne, J. A.; McCullagh, C.; Dunlop, P. S. M. Electrochemical Investigation of Doped Titanium Dioxide. Int. J. Photoenergy 2008 ID 631597.

83. Vohra, A.; Goswami, D. Y.; Deshpande, D. A.; Block, S. S. Enhanced photocatalytic disinfection of indoor air. Appl. Catal., B 2006, 65, 57-65. 
84. Sökmen, M.; Candan, F.; Sümer, Z. Disinfection of E. coli by the $\mathrm{Ag}-\mathrm{TiO}_{2} /$ UV system: lipidperoxidation. J. Photochem. Photobiol., A 2001, 143, 241-244.

85. Karunakaran, C.; Abiramasundari, G.; Gomathisankar, P.; Manikandan, G.; Anandi, $\mathrm{V}$. Cu-doped $\mathrm{TiO}_{2}$ nanoparticles for photocatalytic disinfection of bacteria under visible light. J. Colloid Interface Sci. 2010, 352, 68-74.

86. Yu, J. C.; Ho, W.; Yu, J.; Yip, H.; Wong, P. K.; Zhao, J. Efficient VisibleLight-Induced Photocatalytic Disinfection on Sulfur-Doped Nanocrystalline Titania. Environ. Sci. Technol. 2005, 39, 1175-1179.

87. Rehman, S.; Ullah, R.; Butt, A. M.; Gohar, N. D. Strategies of making $\mathrm{TiO}_{2}$ and $\mathrm{ZnO}$ visible light active. J. Hazard. Mater. 2009, 170, 560-569.

88. Im, J. S.; Yun, S-M.; Lee, Y-S. Investigation of multielemental catalyst based on decreasing the band gap of titania for enhanced visible light photocatalysis. J. Colloid Interface Sci. 2009, 336, 183-188.

89. Li, Q.; Xie, R.; Li, Y. W.; Mintz, E. A.; Shang, J. K. Enhanced VisibleLight-Induced Photocatalytic Disinfection of E. coli by Carbon-Sensitized Nitrogen-Doped Titanium Oxide. Environ. Sci. Technol. 2007, 41, 5050-5056.

90. Hameed, A.; Gondal, M. A.; Yamani, Z. H. Effect of transition metal doping on photocatalytic activity of $\mathrm{WO}_{3}$ for water splitting under laser illumination: role of 3d-orbitals. Catal. Commun. 2004, 5, 715-719.

91. Bagabas, A.; Gondal, M.; Khalil, A.; Dastageer, A.; Yamani, Z.; Ashameria, M. Laser-induced photocatalytic inactivation of coliform bacteria from water using Pd-loaded nano- $\mathrm{WO}_{3}$. Stud. Surf. Sci. Catal. 2010, 175, 279-282.

92. Rengifo-Herrera, J. A.; Pulgarin, C. Photocatalytic activity of N, S co-doped and $\mathrm{N}$-doped commercial anatase $\mathrm{TiO}_{2}$ powders towards phenol oxidation and E. coli inactivation under simulated solar light irradiation. Sol. Energy 2010, 84, 37-43.

93. Yu, H.; Quan, X.; Zhang, Y.; Ma, N.; Chen, S.; Zhao, H. Electrochemically Assisted Photocatalytic Inactivation of Escherichia coli under Visible Light Using a $\mathrm{ZnIn}_{2} \mathrm{~S}_{4}$ Film Electrode. Langmuir 2008, 24, 7599-7604.

94. Xie, B. Bacterial activity of monoclinic $\mathrm{BiVO}_{4}$ under visible light irradiation. Chin. J. Disinfect. 2010, 1, 14-16.

95. Wang, W.; Yu, Y.; An, T.; Li, G.; Yip, H. Y.; Yu, J. C.; Wong, P. K. Visible-Light-Driven Photocatalytic Inactivation of E. coli K-12 by Bismuth Vanadate Nanotubes: Bactericidal Performance and Mechanism. Environ. Sci. Technol. 2012, 46, 4599-4606.

96. Booshehri, A. Y.; Goh, S. C. K.; Hong, J.; Jiang, R.; Xu, R. Effect of depositing silver nanoparticles on $\mathrm{BiVO}_{4}$ in enhancing visible light photocatalytic inactivation of bacteria in water. J. Mater. Chem. A 2014, 2, 6209-6217.

97. Li, Q.; Li, Y. W.; Wu, P.; Xie, R.; Shang, J. K. Palladium Oxide Nanoparticles on Nitrogen-Doped Titanium Oxide: Accelerated Photocatalytic Disinfection and Post-Illumination Catalytic "Memory". Adv. Mater. 2008, 20, 3717-3723. 
98. Gan, H.; Zhang, G.; Huang, H. Enhanced visible-light-driven photocatalytic inactivation of Escherichia coli by $\mathrm{Bi}_{2} \mathrm{O}_{2} \mathrm{CO}_{3} / \mathrm{Bi}_{3} \mathrm{NbO}_{7}$ composites. $J$. Hazard. Mater. 2013, 250, 131-137.

99. Lin, H-Y.; Lin, H-M. Visible-light photocatalytic inactivation of Escherichia coli by $\mathrm{K}_{4} \mathrm{Nb}_{6} \mathrm{O}_{17}$ and $\mathrm{Ag} / \mathrm{Cu}$ modified $\mathrm{K}_{4} \mathrm{NbO}_{17}$. J. Hazard. Mater. 2012, 217, 231-237.

100. Geim, A. K.; Macdonald, A. H. Graphene: exploring carbon flatland. Phys. Today 2007, 60, 35-41.

101. Geim, A. K.; Novoselov, K. S. The rise of graphene. Nat. Mater. 2007, 6, 183-97.

102. Stetson, J. B.; Mercurio, J.; Rosenwinkel, A.; Bedworth, V. P. Perforated graphene deionization or desalination. U.S. Patent Application 12/868,150, 2012.

103. Fernández-Ibáñez, P.; Polo-López, M. I.; Malato, S.; Wadhwa, S.; Hamilton, J. W. J.; Dunlop, P. S. M.; D’Sa, R.; Magee, E.; O’Shea, K.; Dionysiou, D. D.; Byrne, J. A. Solar photocatalytic disinfection of water using titanium dioxide graphene composites. Chem. Eng. J. 2015, 261, $36-44$.

104. Koenig, P. S.; Wang, L.; Pellegrino, J.; Scott Bunch, J. Selective molecular sieving through porous graphene. Nat. Nanotechnol. 2012, 7, 728-732.

105. Berry, V. Impermeability of graphene and its applications. Carbon 2013, 62, $1-10$.

106. Konatham, D.; Yu, J.; Ho, T. A.; Striolo, A. Simulation insights for graphenebased water desalination membranes. Langmuir 2013, 29, 11884-11897.

107. Loh, K. P.; Bao, Q.; Ang, P. K.; Yang, J. The chemistry of graphene. J. Mater. Chem. 2010, 20, 2277-2289.

108. Wang, E. N.; Karnik, R. Water desalination: Graphene cleans up water. Nat. Nanotechnol. 2012, 7, 552-554.

109. Sint, K.; Wang, B.; Kral, P. Selective Ion Passage through Functionalized Graphene Nanopores. J. Am. Chem. Soc. 2008, 130, 16448-16449.

110. Russo, C. J.; Golovchenko, J. A. Atom-by-atom nucleation and growth of graphene nanopores. Proc. Natl Acad. Sci. U.S.A. 2012, 109, 5953-5957.

111. Cohen-Tanugi, D.; Grossman, J. C. Water Desalination across Nanoporous Graphene. Nano Lett. 2012, 12, 3602-3608.

112. Joshi, R. K.; Carbone, P.; Wang, F. C.; Kravets, V. G.; Su, Y.; Grigorieva, I. V.; Wu, H. A.; Geim, A. K.; Nair, R. R. Precise and Ultrafast Molecular Sieving Through Graphene Oxide Membranes. Science 2014, 343, 752-754.

113. Huang, H.; Song, Z.; Wei, N.; Shi, L.; Mao, Y.; Ying, Y.; Sun, L.; Xu, Z.; Peng, X. Ultrafast viscous water flow through nanostrand-channelled graphene oxide membranes. Nat. Commun. 2013, 4, 1-9.

114. Sun, P.; Liu, H.; Wang, K.; Zhong, M.; Wu, D.; Zhu, H. Ultrafast liquid water transport through graphene-based nanochannels measured by isotope labeling. Chem. Commun. 2015, 51, 3251-3254.

115. Han, Y.; Xu, Z.; Gao, C. Ultrathin Graphene Nanofiltration Membrane for Water Purification. Adv. Funct. Mater. 2013, 23, 3693-3700. 
116. Ganesh, B. M.; Isloor, A. M.; Ismail, A. F. Enhanced hydrophilicity and salt rejection study of graphene oxide-polysulfone mixed matrix membrane. Desalination 2013, 313, 199-207.

117. Chandra, V.; Park, J.; Chun, Y.; Lee, J. W.; Hwang, I.-C.; Kim, K. S. Water-Dispersible Magnetite-Reduced Graphene Oxide Composites for Arsenic Removal. ACS Nano 2010, 4, 3979-3986.

118. Paul, B.; Parashar, V.; Mishra, A. Graphene in the $\mathrm{Fe}_{3} \mathrm{O}_{4}$ nano-composite switching the negative influence of humic acid coating into an enhancing effect in the removal of arsenic from water. Environ. Sci.: Water Res. Technol. 2015, 1, 77-83.

119. Hu, M.; Mi, B. Enabling Graphene Oxide Nanosheets as Water Separation Membranes. Environ. Sci. Technol. 2013, 47, 3715-3723.

120. Goh, P. S.; Ismail, A. F.; Ng, B. C. Carbon nanotubes for desalination: Performance evaluation and current hurdles. Desalination 2013, 308, 2-14.

121. Goh, P. S.; Ismail, A. F. Graphene-based nanomaterial: The state-of-the-art material for cutting edge desalination technology. Desalination 2015, 356, $115-128$.

122. Qu, X.; Alvarez, P. J. J.; Li, Q. Applications of nanotechnology in water and wastewater treatment. Water Res. 2013, 47, 3931-3946.

123. Trujillo-Reyes, J.; Peralta-Videa, J. R.; Gardea-Torresdey, J. L. Supported and unsupported nanomaterials for water and remediation: Are they a useful solution for worldwide pollution? J. Hazard. Mater. 2015, 280, 487-503.

124. Khin, M. M.; Nair, A. S.; Babu, V. J.; Murugan, R.; Ramakrishna, S. A review on nanomaterials for environmental remediation. Energy Environ. Sci. 2012, 5, 8075-8109.

125. Subramani, A.; Jacangelo, J. G. Emerging desalination technologies for water treatment: A critical review. Water Res. 2015, 57, 164-187.

126. Abdallah, H.; Moustafa, A. F.; AlAnezi, A. A.; El-Sayed, H. E. M. Performance of a newly developed titanium oxide nanotubes/ polyethersulfone blend membrane for water desalination using vacuum membrane distillation. Desalination 2015, 346, 30-36.

127. Jain, P. K.; Huang, X. H.; El-Sayed, I. H.; El-Sayed, M. A. Noble Metals on the Nanoscale: Optical and Photothermal Properties and Some Applications in Imaging, Sensing, Biology, and Medicine. Acc. Chem. Res. 2008, 41, $1578-1586$.

128. Kelly, K. L.; Coronado, E.; Zhao, L. L.; Schatz, G. C. The Optical Properties of Metal Nanoparticles: The Influence of Size, Shape and Dielectric Environment. J. Phys. Chem. B 2003, 107, 668-677.

129. Liu, J.; Lu, Y. A Colorimetric Lead Biosensor using DNAzyme-Directed Assembly of Gold Nanoparticles. J. Am. Chem. Soc. 2003, 125, 6642-6643.

130. Liu, J.; Lu, Y. Colorimetric $\mathrm{Cu}^{2+}$ detection with a ligation DNAzyme and nanoparticles. Chem. Commun. 2007, 4872-4874.

131. Annadhasan, M.; Muthukumarasamyvel, T.; Sankar; Babu, V. R.; Rajendiran, N. Green Synthesized Silver and Gold Nanoparticles for Colorimetric Detection of $\mathrm{Hg}^{2+}, \mathrm{Pb}^{2+}$ and $\mathrm{Mn}^{2+}$ in Aqueous Medium. ACS Sustainable Chem. Eng. 2014, 2, 887-896. 
132. Schofield, C. L.; Field, R. A.; Russell, D. A. Glyconanoparticles for the Colorimetric Detection of Cholera Toxin. Anal. Chem. 2007, 79, $1356-1361$.

133. Wang, L.; Zhu, Y.; Xu, L.; Chen, W.; Kuang, H.; Liu, L.; Agarwal, A.; Xu, C.; Kotov, N. A. Side-by-Side and End-to-End Gold Nanorod Assemblies for Environmental Toxin Sensing. Angew. Chem., Int. Ed. 2010, 122, 5604-5607.

134. Ueno, Y.; Nagata, S.; Tsutsumi, T.; Hasegawa, A.; Watanabe, M. F.; Park, H. D.; Chen, G. C.; Chen, G.; Yu, S. Z. Detection of microcystins, a blue-green algal hepatotoxin, in drinking water sampled in Haimen and Fusui, endemic areas of primary liver cancer in China, by highly sensitive immunoassay. Carcinogenesis 1996, 17, 1317-1321.

135. Newman, J. D. S.; Roberts, J. M.; Blanchard, G. J. Optical Organophosphate Sensor Based upon Gold Nanoparticle Functionalized Fumed Silica Gel. Anal. Chem. 2007, 79, 3448-3454.

136. Singh, A. K.; Senapati, D.; Wang, S.; Griffin, J.; Neely, A.; Candice, P.; Naylor, K. M.; Varisli, B.; Kalluri, J. R.; Ray, P. C. Gold Nanorod based selective identification of Escherichia coli Bacteria using Two-Photon Rayleigh Scattering Spectroscopy. ACS Nano 2009, 3, 1906-1912.

137. Nie, S. M.; Emery, S. R. Probing Single Molecules and Single Nanoparticles by Surface-Enhanced Raman Scattering. Science 1997, 275, 1102-1106.

138. Dasary, S. S. R.; Singh, A. K.; Senapati, D.; Yu, H.; Ray, P. C. Gold Nanoparticle Based Label-Free SERS Probe for Ultrasensitive and Selective Detection of Trinitrotoluene. J. Am. Chem. Soc. 2009, 131, 13806-13812.

139. Rule, K. L.; Vikesland, P. J. Surface-Enhanced Resonance Raman Spectroscopy for the Rapid Detection of Cryptosporidium parvum and Giardia lamblia. Environ. Sci. Technol. 2009, 43, 1147-1152.

140. Thotiyl, M. M. O.; Basit, H.; Sánchez, J. A.; Goyer, C.; Coche-Guerente, L.; Dumy, P.; Sampath, S.; Labb, P.; Moutet, J. C. Multilayer assemblies of polyelectrolyte-gold nanoparticles for the electrocatalytic oxidation and detection of arsenic(III). J. Colloid Interface Sci. 2012, 383, 130-139.

141. Rastogi, P. K.; Ganesan, V.; Krishnamoorthi, S. A promising electrochemical sensing platform based on a silver nanoparticles decorated copolymer for sensitive nitrite determination. J. Mater. Chem. A 2014, 2, 933-943.

142. Thiruppathiraja, C.; Saroja, V.; Kamatchiammal, S.; Adaikkappan, P.; Alagar, M. Development of electrochemical based sandwich enzyme linked immunosensor for Cryptosporidium parvum detection in drinking water. $J$. Environ. Monit. 2011, 13, 2782-2787.

143. Chan, W. C. W.; Nie, S. Quantum Dot Bioconjugates for Ultrasensitive Nonisotopic Detection. Science 1998, 281, 2016-2018.

144. Koneswaran, M.; Narayanaswamy, R. Mercaptoacetic acid capped CdS quantum dots as fluorescence single shot probe for mercury(II). Sens. Actuators, B 2009, 139, 91-96.

145. Duan, J.; Jiang, X.; Ni, S.; Yang, M.; Zhan, J. Facile synthesis of N-acetyl-Lcysteine capped $\mathrm{ZnS}$ quantum dots as an eco-friendly fluorescence sensor for $\mathrm{Hg}^{2+}$. Talanta 2011, 85, 1738-1743. 
146. Cai, Z.; Shi, B.; Zhao, L.; Ma, M. Ultrasensitive and rapid lead sensing in water based on environmentally friendly and high luminescent L-glutathionecapped-ZnSe quantum dots. Spectrochim. Acta, Part A 2012, 97, 909-914.

147. United States Environmental Protection Agency. http://water.epa.gov/drink/ contaminants/\#seven (accessed May 6, 2015).

148. Wu, C-S.; Oo, M. K. K.; Fan, X. Highly sensitive multiplexed heavy metal detection using quantum dot labeled DNAzymes. ACS Nano 2010, 4, 5897-5904.

149. Hahn, M. A.; Keng, P. C.; Krauss, T. D. Flow Cytometric Analysis to Detect Pathogens in Bacterial Cell Mixtures Using Semiconductor Quantum Dots. Anal. Chem. 2008, 80, 864-872.

150. Agrawal, S.; Morarka, A.; Bodas, D.; Paknikar, K. M. Multiplexed Detection of Waterborne Pathogens in Circular Microfluidics. Appl. Biochem. Biotechnol. 2012, 167, 1668-1677.

151. Liu, G; Lin, Y; Tu, Y; Ren, Z Ultrasensitive voltammetric detection of trace heavy metal ions using Carbon nanotube Nanoelectrode Array. Analyst 2005, 130, 1098-1101.

152. Morton, J.; Havens, N.; Mugweru, A.; Wanekaya, A. K. Detection of Trace Heavy Metal Ions using Carbon Nanotube-Modified Electrodes. Electroanalysis 2009, 21, 1597-1603.

153. Liu, G.; Lin, Y. Biosensor Based on Self-Assembling Acetylcholinesterase on Carbon Nanotubes for Flow Injection/Amperometric Detection of Organophosphate Pesticides and Nerve Agents. Anal Chem. 2006, 78, 835-843.

154. Wang, L.; Chen, W.; Xu, D.; Shim, B. S.; Zhu, Y.; Sun, F.; Liu, L.; Peng, C.; Jin, Z.; Xu, C.; Kotov, N. A. Simple, Rapid, Sensitive and Versatile SWNTPaper Sensor for Environmental Toxin Detection Competitive with ELISA. Nano Lett. 2009, 9, 4147-4152.

155. Prieto-Simón, B.; Bandaru, N. M.; Saint, C.; Voelcker, N. H. Tailored carbon nanotube immunosensors for the detection of microbial contamination. Biosens. Bioelectron. 2015, 67, 642-648.

156. Novoselev, K. S.; Geim, A. K.; Morosov, S. V.; Jiang, D.; Zhang, Y.; Dubonos, S. V.; Grigorieve, I. V.; Firsov, A. A. Electric Field Effect in Atomically Thin Carbon Films. Science 2004, 306, 666-669.

157. Balandin, A. A.; Ghosh, S.; Bao, W. Z.; Calizo, I.; Teweldebrhan, D.; Miao, F.; Lau, C. N. Superior Thermal Conductivity of Single-Layer Graphene. Nano Lett. 2008, 8, 902-907.

158. Service, R. F. Carbon Sheets an Atom Thick Give Rise to Graphene Dreams. Science 2009, 324, 875-877.

159. Lee, C.; Wei, X. D.; Kysar, J. W.; Hone, J. Measurement of the Elastic Properties and Intrinsic Strength of Monolayer Graphene. Science 2008, 321, 385-388.

160. Wu, L.; Fu, X.; Liu, H.; Li, J.; Song, Y. Comparative study of graphene nanosheet- and multiwall carbon nanotube-based electrochemical sensor for the sensitive detection of cadmium. Anal. Chim. Acta 2014, 851, 43-48.

161. Li, J.; Li, J.; Feng, H.; Zhang, Y.; Jiang, J.; Feng, Y.; Chen, M.; Qian, D. A facile one-step in situ synthesis of copper nanostructures/graphene oxide as 
an efficient electrocatalyst for 2-naphthol sensing application. Electrochim. Acta 2015, 153, 352-360.

162. Li, X. R.; Liu, J.; Kong, F. Y.; Liu, X. C.; Xu, J. J.; Chen, H. Y. Potassium doped graphene for simultaneous detection of nitrite and sulfite in polluted water. Electrochem. Commun. 2012, 20, 109-112.

163. Wen, Y.; Xing, F.; He, S.; Song, S.; Wang, L.; Long, Y.; Li, D.; Fan, C. A graphene based fluorescent nanoprobe for silver (1) ions detection by using graphene oxide and a silver-specific oligonucleotide. Chem. Commun. 2010, 46, 2596-2598. 